\title{
Canadian Airway Focus Group updated consensus-based recommendations for management of the difficult airway: part 1. Difficult airway management encountered in an unconscious patient
}

\section{Mise à jour des lignes directrices consensuelles pour la prise en charge des voies aériennes difficiles du Canadian Airway Focus Group: $1^{\text {ère }}$ partie. Prise en charge de voies aériennes difficiles chez un patient inconscient}

\author{
J. Adam Law, MD (D) Laura V. Duggan, MD • Mathieu Asselin, MD • \\ Paul Baker, MBChB, MD • Edward Crosby, MD • Andrew Downey, MBBS • \\ Orlando R. Hung, MD • Philip M. Jones, MD, MSc • François Lemay, MD • \\ Rudiger Noppens, MD, PhD • Matteo Parotto, MD, PhD • Roanne Preston, MD • \\ Nick Sowers, MD • Kathryn Sparrow, MD • Timothy P. Turkstra, MD, MEng • \\ David T. Wong, MD • George Kovacs, MD, MHPE • \\ for the Canadian Airway Focus Group
}

Received: 19 October 2020/Revised: 11 March 2021/Accepted: 14 March 2021/Published online: 18 June 2021 (C) The Author(s) 2021

\begin{abstract}
Purpose Since the last Canadian Airway Focus Group (CAFG) guidelines were published in 2013, the literature on airway management has expanded substantially. The $C A F G$ therefore re-convened to examine this literature and update practice recommendations. This first of two articles
\end{abstract}

The members of the Canadian Airway Focus Group are listed in Appendix.

\section{J. A. Law, MD ( $\square)$}

Department of Anesthesia, Pain Management and Perioperative Medicine, QEII Health Sciences Centre, Dalhousie University, Halifax Infirmary Site, 1796 Summer Street, Room 5452,

Halifax, NS B3H 3A7, Canada

e-mail: jlaw@dal.ca

\section{V. Duggan, MD}

Department of Anesthesiology and Pain Medicine, The Ottawa Hospital Civic Campus, University of Ottawa, Room B307, 1053 Carling Avenue, Mail Stop 249, Ottawa, ON K1Y 4E9, Canada

M. Asselin, MD

Département d'anesthésiologie et de soins intensifs, Université Laval, 2325 rue de l'Université, Québec, QC G1V 0A6, Canada addresses difficulty encountered with airway management in an unconscious patient.

Source Canadian Airway Focus Group members, including anesthesia, emergency medicine, and critical care physicians, were assigned topics to search. Searches were run in the Medline, EMBASE, Cochrane Central

P. Baker, MBChB, MD

Department of Anaesthesiology, Faculty of Medical and Health Science, University of Auckland, Private Bag 92019, Auckland 1142, New Zealand

E. Crosby, MD

Department of Anesthesiology and Pain Medicine, The Ottawa Hospital, University of Ottawa, Suite CCW1401, 501 Smyth Road, Ottawa, ON K1H 8L6, Canada

A. Downey, MBBS

Department of Anaesthesia, Perioperative and Pain Medicine, Peter MacCallum Cancer Centre, Melbourne, Australia

O. R. Hung, MD

Department of Anesthesia, Pain Management and Perioperative Medicine, QEII Health Sciences Centre, Dalhousie University, 1796 Summer Street, Halifax, NS B3H 3A7, Canada 
Register of Controlled Trials, and CINAHL databases. Results were presented to the group and discussed during video conferences every two weeks from April 2018 to July 2020. These CAFG recommendations are based on the best available published evidence. Where high-quality evidence was lacking, statements are based on group consensus.

Findings and key recommendations Most studies comparing video laryngoscopy (VL) with direct laryngoscopy indicate a higher first attempt and overall success rate with VL, and lower complication rates. Thus, resources allowing, the CAFG now recommends use of VL with appropriately selected blade type to facilitate all tracheal intubations. If a first attempt at tracheal intubation or supraglottic airway (SGA) placement is unsuccessful, further attempts can be made as long as patient ventilation and oxygenation is maintained. Nevertheless, total attempts should be limited (to three or fewer) before declaring failure and pausing to consider "exit strategy" options. For failed intubation, exit strategy options in the still-oxygenated patient include awakening (if feasible), temporizing with an SGA, a single further attempt at tracheal intubation using a different technique, or front-of-neck airway access (FONA). Failure of tracheal intubation, face-mask ventilation, and SGA ventilation together with current or imminent hypoxemia defines a "cannot ventilate, cannot oxygenate" emergency. Neuromuscular blockade should be confirmed or established, and a single final attempt at face-mask ventilation, SGA placement, or tracheal intubation with

P. M. Jones, MD, MSc

Department of Anesthesia \& Perioperative Medicine,

Department of Epidemiology \& Biostatistics, Schulich School of

Medicine \& Dentistry, University of Western Ontario, LHSC-

University Hospital, 339 Windermere Rd., London, ON N6A

5A5, Canada

F. Lemay, MD

Département d'anesthésiologie, CHU de Québec - Université

Laval, Hôtel-Dieu de Québec, 11, Côte du Palais, Québec, QC G1R 2J6, Canada

R. Noppens, MD, PhD - T. P. Turkstra, MD, MEng

Department of Anesthesia \& Perioperative Medicine, Schulich School of Medicine \& Dentistry, University of Western Ontario, LHSC- University Hospital, 339 Windermere Road, London, ON N6A 5A5, Canada

\section{Parotto, MD, $\mathrm{PhD}$}

Department of Anesthesiology and Pain Medicine, University of Toronto, Toronto General Hospital, Toronto, ON, Canada

Interdepartmental Division of Critical Care Medicine, University of Toronto, EN 442200 Elizabeth St, Toronto, ON M5G 2C4, Canada hyper-angulated blade VL can be made, if it had not already been attempted. If ventilation remains impossible, emergency FONA should occur without delay using a scalpel-bougie-tube technique (in the adult patient). The CAFG recommends all institutions designate an individual as "airway lead" to help institute difficult airway protocols, ensure adequate training and equipment, and help with airway-related quality reviews.

\section{Résumé}

Objectif Depuis la dernière publication des lignes directrices du Canadian Airway Focus Group (CAFG) en 2013, la littérature sur la prise en charge des voies aériennes s'est considérablement étoffée. Le CAFG s'est donc réuni à nouveau pour examiner la littérature et mettre à jour ses recommandations de pratique. Ce premier article de deux traite de la prise en charge des voies aériennes difficiles chez un patient inconscient.

Sources Des sujets de recherche ont été assignés aux membres du Canadian Airway Focus Group, qui compte des médecins anesthésistes, urgentologues et intensivistes. Les recherches ont été menées dans les bases de données Medline, EMBASE, Cochrane Central Register of Controlled Trials et CINAHL. Les résultats ont été présentés au groupe et discutés lors de vidéoconférences toutes les deux semaines entre avril 2018 et juillet 2020. Les recommandations du CAFG sont fondées sur les meilleures données probantes publiées. Si les données probantes de haute qualité manquaient, les énoncés se fondent alors sur le consensus du groupe.

\section{R. Preston, MD}

Department of Anesthesia, BC Women's Hospital, 4500 Oak Street, Vancouver, BC V6H 3N1, Canada

N. Sowers, MD · G. Kovacs, MD, MHPE

Department of Emergency Medicine, QEII Health Sciences Centre, Dalhousie University, 1796 Summer Street, Halifax, NS B3H 3A7, Canada

K. Sparrow, MD

Discipline of Anesthesia, St. Clare's Mercy Hospital, Memorial University of Newfoundland, 300 Prince Phillip Drive, St. John's, NL A1B V6, Canada

D. T. Wong, MD

Department of Anesthesia, Toronto Western Hospital, University Health Network, University of Toronto, 399, Bathurst St, Toronto, ON M5T2S8, Canada 
Constatations et recommandations clés La plupart des études comparant la vidéolaryngoscopie à la laryngoscopie directe indiquent un taux de réussite plus élevé à la première tentative et globalement avec la vidéolaryngoscopie, ainsi que des taux de complication inférieurs. Ainsi, les ressources le permettant, le CAFG recommande dorénavant l'utilisation de vidéolaryngoscopes avec le type de lame convenablement sélectionné pour faciliter toutes les intubations trachéales. En cas d'échec de la première tentative d'intubation trachéale ou d'échec de positionnement du dispositif supraglottique (DSG), d'autres tentatives peuvent être entreprises tant que la ventilation et l'oxygénation $d u$ patient le permettent. Néanmoins, le nombre total de tentatives devrait être limité, à trois ou moins, avant de déclarer un échec et de considérer les options de " stratégie de retrait ». En cas d'échec de l'intubation, les options de stratégie de retrait chez un patient toujours oxygéné comprennent l'éveil (si possible), la temporisation avec un DSG, une dernière tentative d'intubation trachéale à l'aide d'une technique différente, ou une cricothyroidotomie. L'échec de l'intubation trachéale, de la ventilation au masque facial et de la ventilation via un DSG accompagné d'une hypoxémie présente ou imminente, définit une urgence "impossible de ventiler, impossible d'oxygéner ». Le bloc neuromusculaire doit alors être confirmé ou mis en place, et une tentative finale de ventilation au masque, de positionnement du DSG ou d'intubation trachéale avec une lame de vidéolaryngoscopie hyper-angulée peut être réalisée, si cette approche n'a pas encore été essayée. Si la ventilation demeure impossible, une cricothyroïlotomie d'urgence devrait être réalisée sans delai utilisant une technique de scalpel-bougie-tube (chez le patient adulte). Le CAFG recommande à toutes les institutions de désigner une personne comme "leader des voies aériennes 》 afin d'assister à la mise en place de protocoles pour les voies aériennes difficiles, d'assurer une formation et un équipement adéquats et d'aider aux examens de la qualité en rapport avec les voies aériennes.

Keywords guidelines · airway management · difficult · failed $\cdot$ intubation $\cdot$ tracheal

\section{Disclaimer}

These recommendations aim to reflect the latest published evidence regarding airway management. Where highquality evidence is lacking, expert opinion and consensus is presented. The recommendations do not represent standards of care, and instead are suggestions for optimal practice. They should be applied with specific consideration of the individual patient's characteristics, the clinical context, the airway manager's skills, available resources, and local institutional policies.

\section{Introduction}

Morbidity related to airway management continues to be reported in closed legal claims ${ }^{1,2}$ and practice audits. ${ }^{3,4}$ When such adverse airway outcomes are subject to peer review and analysis, patterns of care are often found to be suboptimal. ${ }^{1-3}$ Common themes include persistence with one technique when tracheal intubation proves difficult; failure to recognize an evolving "cannot ventilate, cannot oxygenate" (CVCO) scenario and failure to perform timely emergency front-of-neck airway access (eFONA) when indicated. Failure of non-technical skills such as effective communication and good team dynamics have often also contributed to airway-related morbidity. ${ }^{1-3}$ With previous guidelines published in $1998^{5}$ and $2013,{ }^{6,7}$ this update to Canadian airway management recommendations reflects new evidence and opinion appearing in the literature. It applies to difficulty encountered with airway management in an unconscious and often apneic patient.

Significant difficulty with airway management in the unconscious patient can often be avoided by careful airway evaluation before the induction of general anesthesia. In part 2 of these updated recommendations, ${ }^{8}$ we have addressed decision-making and implementation of the planned airway strategy for the patient with an anticipated difficult airway. Recommendations in both articles are meant to be broadly applicable to all specialties involved in airway management.

\section{Methods}

The Canadian Airway Focus Group (CAFG) comprises 17 members (see Appendix), with representation from across Canada as well as one member each from New Zealand and Australia. The CAFG membership includes anesthesiologists, emergency physicians, and critical care physicians. Topics for review were divided among the members, with most assigned to two members. Members reviewed the literature published from 2011 onwards.

A medical librarian helped design and conduct the literature searches. Though not constituting a formal systematic review, databases searched included Medline, EMBASE, Cochrane Central Register of Controlled Trials, and CINAHL. Non-English and non-French, animal, manikin, and cadaver studies were excluded, as were case reports, editorials, and letters. Nevertheless, team 
members had discretion to include such material where relevant.

The CAFG met every two weeks via videoconference from April 2018 to July 2020 to review findings and arrive at consensus regarding recommendations. Similar to other airway management guidelines, ${ }^{9-12}$ we did not assign levels of evidence or strength of recommendation. This follows from a lack of what is considered high-level evidence seen in other medical fields. Randomized controlled trials of airway devices typically address efficacy (often in a population of low-risk elective surgical patients) but when critical events are uncommon (as with airway management), they are unable to evaluate the safety of techniques or decision-making. ${ }^{13}$ Information gleaned from large database studies is better able to capture uncommon events, ${ }^{13}$ but analysis is limited to association rather than causation, and the population studied may not represent all practice environments. Thus, although evidence-based to the extent possible, some of the recommendations that follow are based largely on expert consensus.

After review by the CAFG, draft documents were sent to several international airway experts (see Acknowledgments) for informal review and comment.

\section{Definitions}

The following definitions are used throughout the manuscript:

- Difficult airway. A difficult airway exists when an experienced airway manager anticipates or encounters difficulty with any or all of laryngoscopy or tracheal intubation, face-mask ventilation (FMV), supraglottic airway (SGA) use, or eFONA. The airway extends from the nostrils and lips to the alveoli, and anatomical variation or pathological distortion anywhere along its length may cause difficulty. Physiologic or contextual issues may compound difficulty with airway management.

- Difficult and failed face-mask ventilation. Difficulty with or the failure of FMV can be described according to the four-grade scale presented in Table $1 .{ }^{14,15}$ Grades 3 and 4 correspond to difficult and failed ventilation, respectively. The CAFG does not include the number of hands used for a mask seal (i.e., 1 vs 2) in its definition of difficulty, recognizing that the use of two hands may simply reflect clinician preference or the need to optimize a seal to minimize patient exhalation/air leak to the environment.

- Difficult and failed supraglottic airway use. Supraglottic airway use is difficult when more than one attempt at insertion is required, or the resulting ventilation is inadequate. Failed use of an SGA is defined by inadequate ventilation and oxygenation after a maximum of three attempts. As with FMV, this will be reflected by an absent or severely attenuated capnography trace.

- Difficult and failed direct or video laryngoscopy. The view obtained during direct laryngoscopy (DL) or video laryngoscopy (VL) is typically quantified using the Cormack-Lehane ${ }^{16}$ grade or one of its modifications ${ }^{17,18}$ (Table 2). Secretions, blood, emesis, and fogging or illumination issues can also cause difficulty with laryngoscopy. Difficult laryngoscopy is generally described as a CormackLehane grade $2 b$ or $3 a$ view and does not necessarily imply that difficult or failed tracheal intubation will follow. Grade $3 b$ and 4 views define failed DL or VL.

- Difficult and failed tracheal intubation. Tracheal intubation is considered difficult if more than one attempt at optimized laryngoscopy and tracheal tube passage is made, a more experienced operator is required, or a change is made in technique/device. Tracheal intubation has failed if the patient is not intubated after a maximum of three attempts by an experienced airway manager. The definition of failed intubation exists not to be pejorative, but to serve notice to the airway manager that help should be sought and an alternate course of action pursued.

- "Cannot ventilate, cannot oxygenate". The CVCO situation has occurred if attempts to ventilate the patient with all three of tracheal intubation, FMV, and an SGA have failed (i.e., cannot ventilate), resulting in imminent or current hypoxemia (i.e., cannot oxygenate). After much discussion, the CAFG has chosen to introduce the term CVCO rather than referring to "cannot intubate, cannot oxygenate" (CICO) for two reasons. First, it helps de-emphasize what may have been an inappropriate focus on tracheal intubation given that the physiologic endpoints of ventilation and oxygenation are the more important goals. Historically, this might have led to persistence with multiple futile attempts at tracheal intubation in the imminently or already hypoxemic patient and may have failed to prompt an attempt at ventilation using an SGA. Secondly, it acknowledges that the absent or severely attenuated waveform capnography that accompanies each of failed tracheal intubation, FMV, and SGA use (i.e., cannot ventilate) will sometimes precede significant oxygen desaturation, especially in the well pre-oxygenated patient (or possibly, when apneic oxygenation is in use). This window of imminent hypoxemia, between the recognition of the "cannot ventilate" situation and the onset of severe 
Table 1 Grading scale and clinical indicators for ease of face-mask ventilation (after Han et al. ${ }^{14}$ and Lim et al. ${ }^{15}$ )

\begin{tabular}{|c|c|c|c|}
\hline Grade & Description & Ease & Example clinical/monitoring indicators \\
\hline Grade 0 & Face-mask ventilation not attempted & \multirow{3}{*}{ Easy } & \multirow{3}{*}{$\begin{array}{l}\text { Plateau phase is present on capnograph; chest rise occurs } \\
\text { with positive pressure ventilation (PPV). }\end{array}$} \\
\hline Grade 1 & Successfully ventilated by face mask & & \\
\hline Grade 2 & $\begin{array}{l}\text { Successfully ventilated by face mask with use } \\
\text { of an oral airway or another adjunct; } \\
\text { minimal evidence of leak }\end{array}$ & & \\
\hline Grade 3 & $\begin{array}{l}\text { Ventilation by face mask is inadequate or } \\
\text { unstable, despite optimizing maneuvers }\end{array}$ & Difficult & $\begin{array}{l}\text { Attenuated capnographic trace (no plateau phase occurs); } \\
\text { decreased chest rise with attempted PPV. }\end{array}$ \\
\hline Grade 4 & $\begin{array}{l}\text { Unable to face-mask ventilate, despite } \\
\text { optimizing maneuvers }\end{array}$ & Failed & $\begin{array}{l}\text { There is a flat or severely attenuated capnograph and absent } \\
\text { chest rise with attempted PPV; there is also inadequate } \\
\text { restoration or maintenance of } \mathrm{SpO}_{2} \text {. }\end{array}$ \\
\hline
\end{tabular}

$\mathrm{PPV}=$ positive pressure ventilation; $\mathrm{SpO}_{2}=$ peripheral oxygen saturation by pulse oximetry

Table 2 Grading scale for direct or video laryngoscopy (after Cormack-Lehane, ${ }^{16}$ Yentis $^{17}$ and Cook ${ }^{18}$ )

\begin{tabular}{llll}
\hline Grade & Description & $\begin{array}{l}\text { Ease of } \\
\text { laryngoscopy }\end{array}$ & Ease of tracheal intubation \\
\hline $\begin{array}{l}\text { Grade } 1 \\
\text { Grade 2a }\end{array}$ & $\begin{array}{l}\text { All or most of vocal cords are visible } \\
\text { Partial view of vocal cords can be obtained }\end{array}$ & Easy & Intubation is generally non-problematic \\
Grade 2b & $\begin{array}{l}\text { Only the posterior cartilages are visible } \\
\text { Grade 3a }\end{array}$ & $\begin{array}{c}\text { Only the epiglottis is visible, but it can be } \\
\text { lifted off the posterior pharyngeal wall } \\
\text { Only the epiglottis is visible, and it cannot } \\
\text { be readily elevated }\end{array}$ & Failed \\
Grade 3b & $\begin{array}{c}\text { Neither the epiglottis nor } \\
\text { glottis is visible }\end{array}$ & $\begin{array}{c}\text { Intubation is often manageable with adjuncts, } \\
\text { e.g., a tracheal tube introducer ("bougie") or rigid } \\
\text { or semi-malleable stylet }\end{array}$ \\
Grade 4 & $\begin{array}{c}\text { Intubation is often difficult or impossible; an } \\
\text { alternate device is generally required }\end{array}$ \\
\hline
\end{tabular}

hypoxemia offers the best opportunity for a good patient outcome by promptly performing eFONA.

- Emergency front-of-neck airway access. This refers to emergency access to the trachea via the front of the neck by either cricothyrotomy or tracheotomy. In the hands of non-surgeons, eFONA most often occurs in the adult patient by cricothyrotomy and is considered difficult if it requires more than one attempt.

\section{Incidence of difficult and failed airway management}

Table 3 outlines data from studies in various contexts reporting the frequency of difficult and/or failed FMV, SGA use, tracheal intubation, and eFONA. The studies from which these data are taken are heterogeneous, with inconsistent variables such as patient population, airway manager experience, definitions of difficulty or failure, and the use of neuromuscular blockade. This is likely to explain some of the table's wide-ranging numbers.

\section{Response to difficulty with airway management in the unconscious patient}

Airway managers should be ready with a pre-planned, stepwise approach to managing difficulty with FMV, SGA use, or tracheal intubation.

\subsection{Response to difficult FMV}

Difficult FMV is challenging to reliably predict, ${ }^{19}$ and is often indicated by an attenuated waveform capnography trace. $^{15,71}$ Options for responding to difficult FMV are presented in Table 4.

\subsection{Response to difficult SGA insertion or ventilation}

Although SGAs are used as the intended primary airway technique in many elective surgical procedures, they also play a vital rescue role when a difficult or failed tracheal intubation is encountered in any context. An SGA can also serve as a conduit to facilitate flexible bronchoscope (FB)- 
Table 3 Incidence of difficult and failed airway management by practice location. Note that some definitions of "difficult" and "failed" may differ between the referenced studies and those used in this article

\begin{tabular}{|c|c|c|c|c|c|}
\hline & Operating room & Obstetric anesthesia & $\begin{array}{l}\text { Pediatric } \\
\text { anesthesia }\end{array}$ & $\begin{array}{l}\text { Emergency department or } \\
\text { pre-hospital, MD-performed }\end{array}$ & Critical care \\
\hline Difficult FMV & $0.7-3 \%{ }^{19-22}$ & $\begin{array}{l}7.1 \%^{23} \\
30 \%^{24}\end{array}$ & $6.6 \%-9.5 \% \%^{25,26}$ & Approx. $15 \%{ }^{27}$ & $17 \%^{28}$ \\
\hline Failed or impossible FMV & $0.03-0.2 \%^{19,21,29}$ & $14 \%^{23} 9 \%^{24}$ & No data & $7-18 \% \%^{30,31}$ & No data \\
\hline $\begin{array}{l}\text { Difficult FMV combined with } \\
\text { difficult laryngoscopy/ } \\
\text { intubation }\end{array}$ & $0.3-0.4 \%{ }^{19,22}$ & No data & $12.5 \%^{26}$ & No data & $27 \%^{28}$ \\
\hline Difficult tracheal intubation & $3-8 \%^{19,22,32,33}$ & $1.6-5.7 \%^{23,34-37}$ & $0.2-5.5 \%{ }^{25,26,38,39}$ & $1-11 \%^{27,40-44}$ & $5-23 \%{ }^{28,33,45-47}$ \\
\hline Failed tracheal intubation & $0.006-0.4^{19,48,49}$ & $0-0.7 \%^{23,34-37,50,51}$ & $0.08 \%^{38}$ & $0-6 \%{ }^{44,52-56}$ & $7 \%^{45}$ \\
\hline Difficult SGA use & $0.5 \%{ }^{57}$ & $0-1.7 \%^{37,58-60}$ & $0.4-7.1 \%^{38,61}$ & $7 \%{ }^{62}$ & No data \\
\hline Failed SGA use & $0.2-1 \%^{57,63}$ & $0-25 \% \%^{24,35,37,58-60}$ & $0.08-2 \%{ }^{38,61,64}$ & $2-34 \% \%^{30,65-67}$ & No data \\
\hline CVCO or eFONA & $\begin{array}{l}0.006 \%(\mathrm{ENT} \\
\text { patients } \\
0.2 \%)^{68}\end{array}$ & $0-0.2 \%^{23,24,34,35,37,50}$ & No data & $0.1-0.9 \%{ }^{27,44,53,54,69,70}$ & No data \\
\hline
\end{tabular}

$\mathrm{CVCO}=$ cannot ventilate, cannot oxygenate; eFONA = emergency front of neck airway access; ENT = ear, nose, and throat; FMV = face-mask ventilation; SGA = supraglottic airway

Table 4 Recommended options for responding to difficult face-mask ventilation

\section{Options for responding to difficult face-mask ventilation}

- Ensure adequate depth of anesthesia.

- Use an oropharyngeal airway (routine use is recommended for all emergency airway management). A nasopharyngeal airway is an alternative if the mouth cannot be accessed.

- Use a two-handed mask hold with exaggerated jaw lift; ${ }^{72,73}$ positive pressure ventilation can be performed by an assistant or a ventilator set to pressure control ventilation at $\geq 15-\mathrm{cm} \mathrm{H}_{2} \mathrm{O}^{74,75}$

- Use a thenar eminence ("V-E") grip for two-handed mask seal/jaw lift. ${ }^{72,76}$

- Ensure neuromuscular blockade. ${ }^{63,77}$

- Consider an alternate size or type of face mask to improve the airway seal.

- Perform additional head extension ${ }^{72}$ or lateral head rotation ${ }^{78}$ (if not contraindicated).

- Release any applied cricoid pressure. ${ }^{79}$

- Consider head-up patient positioning (hemodynamics permitting).

- Consider gastric decompression via an orogastric tube if significant gastric distention is suspected.

- Exclude presence of a physical obstruction or compression (e.g., foreign body, tumour, or stenosis) in the upper airway or trachea.

- Progress to an alternate mode of ventilation, e.g., SGA or tracheal intubation. ${ }^{22,80}$

SGA $=$ supraglottic airway

guided tracheal intubation, either in a rescue capacity or as the intended primary technique.

Second-generation SGAs are defined by the presence of an esophageal drainage port and cuff design to help maximize seal. They may or may not also be designed to support FB-guided tracheal intubation. Second-generation devices have some benefit over first-generation devices with respect to addressing aspiration risk, but clinically significant aspiration events are rare so this potential advantage has yet to be proven. Nevertheless, given the potential benefits of second-generation SGAs ${ }^{81}$ and with no reported disadvantages, the $\mathrm{CAFG}$ recommends the routine use of second-generation devices whenever an SGA is needed. Recommended options for SGA insertion troubleshooting appear in Table 5.

\subsection{Response to difficult tracheal intubation facilitated by direct or video laryngoscopy}

Tracheal intubation facilitated by DL or VL comprises two separate actions: visualizing the glottis, followed by intubating the trachea. Difficulty may occur with either or both component(s). 
Table 5 Recommended options for responding to difficult supraglottic airway insertion

Options for responding to difficult supraglottic airway (SGA) insertion

- Ensure an adequate depth of general anesthesia for SGA insertion.

- Unless contraindicated, use a "sniff" position for SGA insertion, with lower neck flexion and head extension. ${ }^{82,83}$

- Consider rotating the SGA $90^{\circ}$ during advancement around the tongue. ${ }^{84-87}$

- Use an alternate size ${ }^{88,89}$ or design of SGA, including one with a different cuff material. ${ }^{90}$

- In the context of failed tracheal intubation, release any applied cricoid pressure for SGA insertion. ${ }^{91-93}$

- Consider neuromuscular blockade (evidence regarding benefit during SGA use is conflicting; however, no harm is reported). ${ }^{94-97}$

- Consider SGA insertion facilitated by direct or video laryngoscopy. ${ }^{89,90,98-102}$ With a second-generation SGA, a tracheal tube introducer ("bougie") placed through the SGA's esophageal drainage port can first be advanced into the esophagus to subsequently help guide the SGA into position. ${ }^{103,104}$

- Progress to an alternate mode of ventilation, e.g., tracheal intubation or FMV.

$\mathrm{FMV}=$ face-mask ventilation; $\mathrm{SGA}=$ supraglottic airway

The terms "direct" and "video" laryngoscopy encompass a variety of devices. For the purposes of the following discussion, we categorize laryngoscopy as follows:

- Direct laryngoscopy refers to use of non-video enabled laryngoscopes, typically with Macintosh or Miller blades. Glottic visualization occurs by direct eye-toglottis sighting.

- Video laryngoscopy refers chiefly to use of laryngoscopes with a camera in the blade that delivers an image to an external video screen. Originally designed with a hyper-angulated blade (HA-VL), video laryngoscopes are now available with varying blade geometries, including Macintosh-shaped video laryngoscopy (Mac-VL). Further details appear in Table 6.

Responses to difficulty with glottic exposure or difficulty with tracheal intubation using DL and Mac-VL appear in Table 7. Unless the glottis is obscured by pathology, ${ }^{122}$ fogging, blood or secretions/emesis in the pharynx, difficult laryngoscopy is unusual when using HAVL, provided the blade can be inserted and placed within the oropharynx. Instead, difficulty with HA-VL facilitated tracheal intubation often relates to difficulty with "around the corner" delivery of the tracheal tube to and through the glottis. Recommended measures to help address difficulty with tracheal tube delivery when using HA-VL are presented in Table 8 .

\subsection{Primary use of video laryngoscopy}

The CAFG studied whether a recommendation could be made for the routine primary use of VL (as opposed to DL) to facilitate tracheal intubation. Unfortunately, the currently available literature comparing Macintosh DL with VL is difficult to interpret. While plentiful, most systematic reviews and meta-analyses comparing DL with VL combine various VL blade types (HA-VL and MacVL), patient populations, clinical contexts, airway manager experience, and measured outcomes. ${ }^{141}$ Nevertheless, compared with DL, the first-attempt and overall success rates of tracheal intubation using VL (Mac-VL or HA-VL) are rarely worse, and are often better. ${ }^{105,113,114,142-153}$

The use of a Mac-VL, ${ }^{106,154} \mathrm{HA}-\mathrm{VL},{ }^{48,155}$ or VL of unspecified blade type ${ }^{37}$ have all been shown to facilitate successful tracheal intubation after failed DL. In addition, there may be lower complication rates with VL, including fewer occurrences of esophageal intubation. ${ }^{52,113,144-147,156-159}$ The use of VL also enables a "shared mental model", helping to increase engagement of all airway team members. On balance, and resources allowing, the CAFG recommends the routine primary use of VL with an appropriate blade type for all tracheal intubations. If difficulty is predicted with glottic exposure using DL or Mac-VL, first-attempt use of HA-VL to facilitate tracheal intubation should be strongly considered. For the patient at risk of upper airway soiling (e.g., blood, emesis), consider using Mac-VL so that direct, eye-toglottis visualization can occur should the video camera become obscured. Intermediate geometry blade VL (e.g., McGrath Mac) or DL are alternatives in this situation.

\section{Response to an unsuccessful first (or subsequent) attempt at the intended airway technique}

The following sections address difficulty and failure encountered with attempted tracheal intubation. The response to difficulty and failure with an SGA is discussed in section 8 . 
Table 6 Video laryngoscope blade types with commonly used examples ( ${ }^{\mathrm{A}}$ Karl Storz Endoscopy America Inc., El Segundo, CA, USA; ${ }^{\mathrm{B}}$ Verathon Inc., Bothell, WA, USA; ${ }^{\mathrm{C}}$ Medtronic Canada, Brampton, ON; ${ }^{\mathrm{D}}$ Ambu, Inc., Columbia, MD, USA; ${ }^{\mathrm{E}}$ Teleflex, Morrisville, NC, USA)

Video laryngoscopy (VL) blade types

Blade type

Comment

Commonly used example(s) laryngoscopy (Mac-VL)
Macintosh geometry video

Using similar technique and optimizing maneuvers as DL, Macintosh geometry VL (Mac-VL) enables laryngeal visualization to occur by direct eye-to-glottis sighting or indirect, on-screen videoscopic sighting. The videoscopic view may be better than that afforded by standard direct laryngoscopy ${ }^{105-107}$ and may ${ }^{108-111}$ or may not ${ }^{12}$ be significantly better than that afforded by direct eye-to-glottis viewing with the same video laryngoscope. Higher firstpass $^{105,113}$ and overall ${ }^{105,114}$ success rates have been reported with Mac-VL than with DL. As with DL, once a view of the glottis is obtained, tracheal tube delivery tends to be straightforward.

Hyper-angulated or hyper-curved blade video laryngoscopy (HA-VL)

Intermediate geometry video laryngoscope blades
Hyper-angulated blade VL (HA-VL) allows "around the corner" viewing of the glottis by indirect, videoscopic viewing only. The view with HA-VL is often superior to that obtained by DL ${ }^{115-117}$ or Mac-VL. ${ }^{117}$ First pass tracheal intubation success with HA-VL is frequently higher than with DL. ${ }^{113}$ Tracheal intubation with HA-VL requires use of a stylet ${ }^{118}$ or other adjunct and for the inexperienced airway manager, may be more challenging or take longer than with DL. ${ }^{119,120}$ This can occur despite good glottic visualization. ${ }^{121,122}$ It is important to maintain direct (i.e., non-videoscopic) intraoral visual contact with the advancing styleted tube until its tip is past the soft palate, to avoid inadvertent soft-tissue injuries. ${ }^{123,124}$ In this regard, a malleable stylet is preferred and equally effective ${ }^{118}$ to a rigid stylet. Some HA-VLs feature an integrated channel in the blade to help safely guide the tracheal tube to the glottis. between that of typical Mac-VL $\left(30^{\circ}\right)$ and HA-VL $\left(60-90^{\circ}\right)$ blades. The view afforded $^{125}$ and ease of tube delivery is correspondingly intermediate between that of Mac-VL and HA-VL. Use of a stylet or a tracheal tube introducer ("bougie") is recommended.
Video laryngoscope blades exist with angulation or curvature intermediate
- C-MAC ${ }^{\circledR}$ with Macintosh blade ${ }^{\mathrm{A}}$

- GlideScope ${ }^{\circledR}$ $\mathrm{DVM}^{\mathrm{B}}$
Non-channelled

- C-MAC ${ }^{\circledR}$ D-blade

- GlideScope ${ }^{\circledR}$

LoPro

- McGrath ${ }^{\mathrm{TM}} \mathrm{Mac}^{\mathrm{C}}$ with $\mathrm{X}$ blade

Channelled

- King Vision ${ }^{\mathrm{TM}} \mathrm{D}$

- $\operatorname{Airtraq}^{\mathrm{TM} \mathrm{E}}$

- McGrath ${ }^{\mathrm{TM}} \mathrm{Mac}^{\mathrm{C}}$ with Mac blade

$\mathrm{DL}$ = direct laryngoscopy; HA-VL = hyper-angulated blade video laryngoscopy; Mac-VL = Macintosh geometry blade video laryngoscopy

Table 7 Recommended options for difficulty encountered with glottic exposure and/or tracheal intubation using DL or Mac-VL

Options for response to difficulty with glottic exposure using direct laryngoscopy (DL), Macintosh geometry blade video laryngoscopy (Mac-VL) or intermediate geometry blade video laryngoscopy

- Ensure neuromuscular blockade.

- Apply external laryngeal manipulation (not cricoid pressure).

- Ensure the Macintosh blade is inserted sufficiently deep into the vallecula to engage the hyoepiglottic ligament.

- Consider directly lifting the epiglottis (applies to both Macintosh and straight blades).

- Exaggerate head lift and "sniff" positions, ${ }^{126-129}$ if not contraindicated.

- Release any applied cricoid pressure. ${ }^{130}$

- If using Mac-VL, switch to indirect, videoscopic viewing ${ }^{108-110}$ if direct eye-to-glottis viewing is suboptimal.

- For continued difficulty with glottic exposure, if the patient remains well-oxygenated, strongly consider progressing to HA-VL. ${ }^{48}$

Options for response to difficulty with tracheal tube passage during DL or Mac-VL

- Use a tracheal tube introducer ("bougie"). The bougie is an effective adjunct when Mac-VL or DL results in a limited (e.g., Cormack-Lehane $2 \mathrm{~b}$ or $3 \mathrm{a}$ ) view. ${ }^{40,131}$ The CAFG endorses the immediate availability of a bougie in all airway management locations.

- If not using a bougie, use a stylet to optimally shape the tracheal tube.

- If difficulty with tube passage has occurred in the context of a suboptimal glottic view, consider progressing to $\mathrm{HA}_{\mathrm{V}} \mathrm{VL}^{48}$ if the patient remains well-oxygenated.

$\mathrm{DL}=$ direct laryngoscopy; HA-VL = hyper-angulated blade video laryngoscopy; Mac-VL = Macintosh geometry blade video laryngoscopy 
Table 8 Recommended options for response to difficulty with tube delivery facilitated by HA-VL

Options for response to difficulty with tracheal tube delivery when using hyper-angulated blade video laryngoscopy (HA-VL)
HA-VL
Partially withdraw the HA-VL blade during laryngoscopy, seeking to achieve no more than a limited view of the larynx
(non-channelled
(e.g., Grade 2$)^{132}$ This allows for both a wider field of view and also a straighter pathway for tube delivery.
- Modify the curvature of the styleted tracheal tube to accommodate specific patient anatomy. When a semi-rigid or
malleable stylet is used to facilitate HA-VL, it should generally be shaped to match the angulation or curvatureof the
blade (i.e., not including the handle) - typically at angles between 60 and $90^{\circ} .{ }^{118,133,134}$
- Centre the view of the glottis on the screen, then slide the styleted tube's tip along the undersurface of the blade to help
direct it to the glottis. ${ }^{135}$
- Withdraw the stylet by 4 cm once the tip of the tracheal tube has been passed through the glottis. By allowing the tracheal
tube to reflect off the anterior tracheal wall, this facilitates its further advancement down the trachea.
- For tube "hang-up" persisting after partial stylet withdrawal, rotation of the tube $45-90^{\circ}$ to the right (clockwise) may
help address tube impingement on the cricoid cartilage or a tracheal ring. ${ }^{135}$
- Insertion of a styleted tube before ${ }^{136}$ or concomitantly with ${ }^{137}$ the videolaryngoscope blade may help with tube passage
in the patient with a small mouth. Note that blind insertion of a styleted tracheal tube is contraindicated in some clinical
circumstances (e.g., retropharyngeal abscess).
- Changing to DL or Mac-VL may succeed if tube delivery continues to be problematic with HA-VL, ${ }^{122,138,139}$ unless
already proven unsuccessful.
- Slight withdrawal, caudad angulation of the blade and lifting of the scope may help better align the advancing tube with
the glottic opening and trachea ${ }^{140}$. It is important to not use too small a tracheal tube, as it can exit the channel in an
excessively caudad direction.

$\mathrm{DL}$ = direct laryngoscopy; HA-VL = hyper-angulated blade video laryngoscopy; Mac-VL = Macintosh geometry blade video laryngoscopy

7.1 The hazards of multiple attempts at tracheal intubation

Airway managers are susceptible to a variety of cognitive biases $^{160}$ that may negatively affect patient care ${ }^{161}$. One of the most concerning is perseveration, defined in the 2019 American Society of Anesthesiologists (ASA) closed claims publication as the "consistent application of any airway management technique or tool more than twice without deviation or change of technique, or the return to a technique or tool that had previously been unsuccessful". 1 Perseveration with multiple tracheal intubation attempts appears to be particularly prevalent in otherwise healthy adults $^{1}$ and in children where no difficulty was anticipated. $^{39}$ Most airway managers recognize that failure of an optimized attempt using one device should mean that another device, technique or operator should be employed during subsequent attempts. Yet even with the substitution of a different device, multiple attempts are correlated with adverse events. Thus, first-attempt success at the intended technique should always be a goal.

Adverse outcomes associated with multiple attempts at tracheal intubation include hypoxemia, esophageal intubation, airway trauma, and cardiac arrest. This association exists in pre-hospital care (if tracheal intubation is used), ${ }^{162,163}$ pediatric settings, ${ }^{164-166}$ critical care, ${ }^{167-169}$ emergency medicine, ${ }^{43,44,170-172}$ and in the operating room $(\mathrm{OR})^{38,39}$ (Table 9). Similar evidence exists regarding multiple attempts at SGA insertion. ${ }^{38,166}$ As a result, virtually all national airway management guidelines in adults, ${ }^{6,9,10,12,71,173-180}$ obstetrics, ${ }^{181,182}$ and pediatrics $^{183-185}$ agree that a maximum of two to four optimized attempts (collectively, by all airway managers involved) at tracheal intubation occur before pausing to consider an alternate ("exit") strategy, with the goal of returning the patient to a point of safety.

\subsection{Unsuccessful first or subsequent attempt at tracheal} intubation with oxygen saturation in a safe range

The following narrative should be read in conjunction with the flow diagram depicted in the Figure. If a first attempt at tracheal intubation is unsuccessful, further attempts at tracheal intubation can be made according to the following guiding principles:

- Further intubation attempts should only be made if the peripheral oxygen saturation $\left(\mathrm{SpO}_{2}\right)$ remains in, or has been returned to, a safe range for the patient (e.g., $\geq$ $90 \%$ ). This may occur by FMV or SGA ventilation, the effectiveness of which can be seen by waveform capnography. It also includes the situation where the patient is not ventilated after an unsuccessful first intubation attempt, but the $\mathrm{SpO}_{2}$ is maintained in a safe range because of pre-oxygenation and/or the use of apneic oxygenation.

- For a further attempt at tracheal intubation, if not already applied, apneic oxygenation should be considered. This can be administered by via conventional nasal prongs at $5-15 \mathrm{~L} \cdot \mathrm{min}^{-1}$ or a high- 
Table 9 The adverse outcomes associated with multiple attempts at tracheal intubation

\begin{tabular}{|c|c|c|c|}
\hline Reference & $\begin{array}{l}\text { Number of } \\
\text { patients }\end{array}$ & Clinical context & Findings \\
\hline Mort $2004^{167}$ & 2,833 & In-hospital, outside of operating room & $\begin{array}{l}>2 \text { attempts associated with increased complications (cardiac } \\
\text { arrest RR, 7; 95\% CI, } 2.4 \text { to 9.9). Recommend maximum of } \\
\text { three attempts. }\end{array}$ \\
\hline $\begin{array}{l}\text { Griesdale et al. } \\
\quad 2008^{168}\end{array}$ & 136 & Critical care unit & $\begin{array}{l}\geq 2 \text { attempts independently associated with increased risk of } \\
\text { severe complications (OR, 3.3; 95\% CI, } 1.3 \text { to } 8.4) \text {. }\end{array}$ \\
\hline $\begin{array}{l}\text { Martin et al. } \\
\quad 2011^{169}\end{array}$ & 3,423 & In-hospital, outside of operating room & $\begin{array}{l}\geq 3 \text { attempts associated with complications }(\mathrm{OR}, 6.7 ; 95 \% \mathrm{CI} \text {, } \\
3.2 \text { to } 14.2) \text {. }\end{array}$ \\
\hline $\begin{array}{l}\text { Hasegawa et al. } \\
2012^{43}\end{array}$ & 2,616 & Emergency department & $\begin{array}{l}\geq 3 \text { attempts associated with adverse events (OR, } 4.5 ; 95 \% \mathrm{CI} \text {, } \\
3.4 \text { to } 6.1)\end{array}$ \\
\hline $\begin{array}{l}\text { Rognås et al. } \\
2013^{162}\end{array}$ & 683 & $\begin{array}{l}\text { Pre-hospital (intubation by experienced } \\
\text { anesthesiologists) }\end{array}$ & $\begin{array}{l}\text { Complication rates: } 7 \% \text { (1 attempt), 23\% (2 attempts) and 32\% } \\
\text { (>2 attempts). }\end{array}$ \\
\hline $\begin{array}{l}\text { Sakles et al. } \\
2013^{170}\end{array}$ & 1,828 & Emergency department & $\begin{array}{l}\text { Adverse event rates: } 14 \% \text { ( } 1 \text { attempt), } 47 \% \text { ( } 2 \text { attempts), } 64 \% \\
\text { (3 attempts), } 71 \% \text { ( } 4 \text { or more attempts). >1 attempt } \\
\text { associated with adverse events (OR, 7.5; } 95 \% \text { CI, } 5.9 \text { to } 9.6)\end{array}$ \\
\hline Kim et al. $2014^{163}$ & 512 & Pre-hospital cardiac arrests & $\begin{array}{l}\text { Failed initial attempt associated with reduced odds of return of } \\
\text { spontaneous circulation (OR, } 0.4 ; 95 \% \mathrm{CI}, 0.23 \text { to } 0.71) \text {. }\end{array}$ \\
\hline $\begin{array}{l}\text { Goto et al. } \\
\quad 2015^{171}\end{array}$ & 4,094 & Emergency department & $\begin{array}{l}\text { Second attempt by same operator associated with lower } \\
\text { success rate (OR, } 0.50 ; 95 \% \mathrm{CI}, 0.36 \text { to } 0.71) \text {. }\end{array}$ \\
\hline $\begin{array}{l}\text { Kerslake et al. } \\
2015^{44}\end{array}$ & 3,738 & Emergency department & $\begin{array}{l}\text { Complication rate: } 7 \% \text { ( } 1 \text { attempt), } 15 \% \text { ( } 2 \text { attempts), } 32 \% \text { ( } 3 \\
\text { attempts). }\end{array}$ \\
\hline $\begin{array}{l}\text { Bodily et al. } \\
\quad 2016^{172}\end{array}$ & 166 & Emergency department & $\begin{array}{l}>1 \text { attempt associated with oxygen desaturation (OR, 3.4; } 95 \% \\
\quad \text { CI, } 1.4 \text { to } 6.1) \text {. }\end{array}$ \\
\hline $\begin{array}{l}\text { Sauer et al. } \\
\quad 2016^{164}\end{array}$ & 308 & $\begin{array}{l}\text { Neonatal intensive care unit: neonates }< \\
750 \mathrm{gm} .\end{array}$ & $\begin{array}{l}\text { Multiple attempts associated with severe intraventricular } \\
\text { hemorrhage (OR, } 1.5 ; 95 \% \mathrm{CI}, 1.1 \text { to } 2.1) \text {. }\end{array}$ \\
\hline Lee et al. $2016^{165}$ & 2,080 & $\begin{array}{l}\text { Pediatric intensive care unit (NEAR4KIDS } \\
\text { database) }\end{array}$ & $\begin{array}{l}\text { Severe oxygen desaturation (defined as }<70 \%) 1 \text { attempt: } \\
12 \% ; 2 \text { attempts: } 30 \%(\mathrm{OR}, 3.1 ; 95 \% \text { CI, } 2.4 \text { to } 4.0) ;>2 \\
\text { attempts: } 44 \% \text { (OR, 5.7; 95\% CI, } 4.3 \text { to } 7.5 \text { ) }\end{array}$ \\
\hline $\begin{array}{l}\text { Fiadjoe et al. } \\
\quad 2016^{39}\end{array}$ & 1,018 & $\begin{array}{l}\text { Pediatric operating room (PeDI registry } \\
\text { reported difficult intubation encounters) }\end{array}$ & $\begin{array}{l}\text { Cumulative risk of complications: } 1 \text { attempt } 13 \% ; 2 \text { attempts } \\
31 \% ; 3 \text { attempts } 53 \% \text {. OR of a complication } 1.5 \text { per attempt } \\
(95 \% \text { CI, } 1.4 \text { to } 1.6) \text {. }\end{array}$ \\
\hline $\begin{array}{l}\text { Engelhardt et al. } \\
2018^{38}\end{array}$ & 31,024 & Pediatric operating room & $\begin{array}{l}\geq 3 \text { attempts at tracheal intubation (RR, } 2.1 ; 95 \% \text { CI } 1.3 \text { to } \\
\text { 3.4) or SGA insertion (RR, } 4.3 ; 95 \% \mathrm{CI}, 1.9 \text { to } 9.9) \\
\text { associated with an increase in critical respiratory events. }\end{array}$ \\
\hline $\begin{array}{l}\text { Stinson et al. } \\
\quad 2018^{166}\end{array}$ & 1,448 & Hospitalized pediatric patients & $\begin{array}{l}\text { Failure of intubation or SGA insertion on } 1 \text { st attempt } \\
\text { associated with progression of acute respiratory compromise } \\
\text { to cardiac arrest (OR, 1.8; 95\% CI, } 1.2 \text { to } 2.6 \text { ). }\end{array}$ \\
\hline $\begin{array}{l}\text { Gálvez et al. } \\
\quad 2019^{186}\end{array}$ & 1,341 & $\begin{array}{l}\text { Infants: Operating room and diagnostic } \\
\text { imaging }\end{array}$ & $\begin{array}{l}2 \text { or more attempts associated with increased odds ratio of } \mathrm{SpO}_{2} \\
\quad<90 \% \text { for at least one minute (OR, 1.78; } 95 \% \mathrm{CI}, 1.3 \text { to } \\
2.4 \text { ). }\end{array}$ \\
\hline $\begin{array}{l}\text { Amalric et al. } \\
\quad 2020^{187}\end{array}$ & 202 & Critical care & $\begin{array}{l}\text { Complications occurred in } 11 \% \text { of those intubated on the first } \\
\text { attempt; } 32 \% \text { with } \geq 2 \text { attempts }(P<0.001) \text {. }\end{array}$ \\
\hline
\end{tabular}

$\mathrm{CI}=$ confidence interval; $\mathrm{OR}=$ odds ratio; $\mathrm{RR}=$ relative risk; $\mathrm{SpO}_{2}=$ peripheral oxygen saturation by pulse oximetry

flow humidified device at $50-70 \mathrm{~L} \cdot \mathrm{min}^{-1}$ in adults; pediatric flows are weight-based. ${ }^{188}$

- A second attempt at tracheal intubation should address the likely cause of the previous unsuccessful attempt and not simply repeat a technique already shown to have failed. Examples include: 1) an unsuccessful intubation attempt due to poor view (e.g., Cormack-
Lehane grade $2 \mathrm{~b}$ or $3 \mathrm{a}$ [Table 2]) obtained with DL or Mac-VL might be managed on a second attempt by adjunctive use of a tracheal tube introducer ("bougie"); 2) a Cormack-Lehane grade 3 b or 4 glottic view on a first attempt might be addressed on a second attempt by use of HA-VL to improve glottic exposure; ${ }^{139,189} 3$ ) unsuccessful tracheal intubation due to difficulty with 
tracheal tube passage through the glottis despite good laryngeal exposure on a first attempt with HA-VL might be addressed on a second attempt by using MacVL or DL to help straighten the pathway for tracheal tube delivery; ${ }^{139,189}$ and 4) an inexperienced airway manager might have a more experienced airway manager perform a subsequent intubation attempt with the same or a different device.

- A third attempt should only be made with a substantive change of technique, device, or airway manager, and again, only if the patient remains well-oxygenated. If not already attempted, use of HA-VL and/or a FB should be considered, assuming that the device and a clinician skilled in its use is available.

- If the patient is still not tracheally intubated after a maximum of three attempts but ventilation and oxygenation continue to be non-problematic, the airway manager should verbally declare a "failed intubation" situation, call for help, and pause to consider exit strategy options. The verbal declaration (e.g., "This is a failed intubation situationoxygenation is being maintained, but we will need help and must move on to doing something different") will help alert all team members to the evolving risk to the patient.

- Based on a first or second attempt, it may be evident that any further attempts at tracheal intubation are futile with standard or available methods, or in that airway manager's hands. Immediately pausing to think about exit strategy options would be appropriate.

\subsection{Exit strategy options after failed tracheal} intubation, with $\mathrm{SpO}_{2}$ in a safe range

Once a failed tracheal intubation situation has been declared and help summoned, the airway manager should maintain patient ventilation and oxygenation (e.g., often with FMV, but optionally with an SGA), retain composure, and consider an appropriate exit strategy. If not already done, anterior neck landmarks should be assessed for the location of the cricothyroid membrane, in case eFONA becomes necessary. Exit strategy options include the following:

\section{A. Awaken the patient}

If feasible, when both ventilation and oxygenation are non-problematic, allowing the patient to emerge from general anesthesia after failed tracheal intubation may prevent deterioration to a CVCO scenario. Airway patency and gas exchange can be supported using FMV or an SGA until spontaneous ventilation resumes and the patient can maintain airway patency without assistance. The status of any neuromuscular blockade and sedative agents must be assessed and managed (e.g., with medications such as sugammadex,${ }^{190}$ naloxone, or flumazenil, as appropriate). Once a patient has emerged from general anesthesia, options include regional anesthesia, deferring elective surgery, or if the surgery is urgent, immediate awake oral/nasal tracheal intubation, or awake tracheotomy.

Awakening the patient after failed tracheal intubation in the context of a surgical emergency or critical illness (as with most emergency department or critical care intubations) might not be possible or appropriate, as the patient's clinical trajectory with deteriorating course over time may preclude a return to a functional respiratory or cognitive state. In this case, other exit strategy options should be considered.

\section{B. Temporize with an SGA}

An SGA can be placed after failed tracheal intubation to temporize (e.g., pending the arrival of additional equipment or expertise) or to support the airway while the patient emerges from general anesthesia. In general, when tracheal intubation was the intended technique for an elective surgical case but has failed, proceeding with the case using only the SGA is inadvisable. ${ }^{3}$ This follows from the trauma and swelling to the larynx that may have occurred with the preceding attempts at tracheal intubation. Also, if subsequent intraoperative SGA malfunction occurs, the fallback option of tracheal intubation has already proven to have failed. Nevertheless, in certain contexts (e.g., emergency Cesarean delivery $[C D]$ ), the potential benefit of proceeding with a surgical procedure with an SGA after failed tracheal intubation may exceed the risk, although the risk of aspiration must be considered. A second-generation SGA should be used (ideally one that also supports FB-guided intubation) and a plan for intraoperative SGA failure should be considered.

The critically ill non-surgical patient successfully temporized by SGA or FMV after failed tracheal intubation will likely still require timely tracheal intubation (see next section) or FONA.

\section{Proceed with a further attempt at tracheal intubation}

Pausing to consider exit strategy options after a maximum of three attempts at tracheal intubation helps to both avoid perseveration with failed techniques and maintain situational awareness. It does not absolutely preclude another attempt at tracheal intubation. Nevertheless, a further intubation attempt should only be considered as an exit strategy option with the following provisos: 1) ventilation and oxygenation by FMV or an SGA remain non-problematic; 2) the patient has already undergone prior attempts at tracheal intubation and the larynx may have been subjected to trauma, so an exit strategy intubation should be limited to a single attempt by an airway manager experienced with the planned 
technique; 3) the planned technique should have a high likelihood of addressing the anatomic constraints that contributed to the earlier failure(s); and 4) a second airway manager should be present. The intubation technique is chosen according to clinical judgement. Nevertheless, if not already attempted, an FB can often prove effective, used on its own or in conjunction with another device:

- Flexible bronchoscope use on its own: When used on its own, an intubating oropharyngeal airway ${ }^{48}$ (e.g., Williams, Berman, or Ovassapian) can aid with FB intubation in the unconscious patient. Manual tongue extraction or a jaw thrust by a second individual can enhance the pharyngeal space for FB navigation and optimize apneic oxygenation.

- Flexible bronchoscope-guided intubation through an SGA: This technique has a high success rate in experienced hands and should ideally proceed through an SGA designed to support tracheal intubation. ${ }^{191}$ It can also occur through non-intubating SGAs using an Aintree intubation catheter (Cook Inc., Bloomington, IN, USA) as an airway adjunct. ${ }^{192}$

- Flexible bronchoscope used in combination with VL: This is an effective combination, ${ }^{48,193-195}$ with each device working synergistically to address the limitations of the other. Once well advanced into the trachea, the FB acts as an extended flexible stylet to facilitate tracheal intubation, addressing the issue of difficult tracheal tube delivery with HA-VL used on its own. Similarly, the VL controls collapsing soft tissues in the anesthetized patient to create a patent pharyngeal conduit through which to advance the FB, and also enables visualization of tracheal tube passage through the larynx over the FB. Using both devices together may increase success more than using either device alone, but it does require practice in co-ordinating the tasks of two airway managers-i.e., one to maintain a stable VL view while another manages the FB. Apneic oxygenation should be used throughout.

A successful exit strategy tracheal intubation should prompt the airway manager to carefully consider a safe tracheal extubation strategy (see companion article). ${ }^{8}$ Conversely, failure of an exit strategy tracheal intubation attempt should prompt re-consideration of other exit strategy options, including awakening the patient, temporizing with an SGA, or proceeding to FONA.

\section{Front-of-neck (surgical) airway access}

Although very rarely indicated in the still-oxygenated elective surgical patient, this option may be appropriate after failed tracheal intubation of a critically ill patient, or for the patient requiring emergency surgery. Patient ventilation and oxygenation may be maintained by FMV or an SGA while FONA is performed by cricothyrotomy or tracheotomy.

\subsection{The "cannot ventilate, cannot oxygenate" situation}

The CVCO situation is defined as the failure of tracheal intubation, face-mask-, and SGA ventilation (cannot ventilate), resulting in current or imminent hypoxemia (cannot oxygenate). Thus, in the context of tracheal intubation, this means that one or more intubation attempts has failed and, despite fallback attempts at ventilating and oxygenating the patient by optimized FMV and SGA ventilation, the patient is:

- Currently hypoxemic (e.g., $\mathrm{SpO}_{2}$ is $<90 \%$ )

- Imminently hypoxemic $\left(\mathrm{SpO}_{2}\right.$ is currently $\geq 90 \%$-e.g., because of pre-oxygenation or the use of apneic oxygenation-but an absent or severely attenuated waveform capnograph for all of tracheal intubation, FMV, and SGA use has indicated a "can't ventilate" situation, so that hypoxemia will likely rapidly follow).

Depicted on the right-hand side of the Figure, the CVCO situation should be managed according to the following guiding principles:

- Once recognized, the CVCO situation should be verbally declared (e.g., "This is a can't ventilate, can't oxygenate situation and we need to perform a cricothyrotomy immediately") and eFONA should proceed without delay. It is worth emphasizing that it is not desirable to allow hypoxemia to occur before transitioning to eFONA when hypoxemia is a predictable consequence of the "cannot ventilate" situation. Successfully performing eFONA before severe or prolonged hypoxemia has occurred in a CVCO situation will maximize the possibility of a good outcome.

- Help should be summoned.

- Equipment for eFONA should be obtained, the anterior neck quickly landmarked and the most qualified person already present should be delegated to perform eFONA.

Concurrent with the foregoing preparations for beginning eFONA, neuromuscular blockade should be confirmed or established, especially if tracheal intubation had proceeded with succinylcholine or without neuromuscular blockade. FMV generally gets easier with the onset of neuromuscular blockade or, at worst, remains unchanged. ${ }^{77,196-199}$ It may also facilitate SGA placement and performing eFONA. In addition to neuromuscular blockade, a single attempt at any or all of the following should be made, if not yet attempted: 


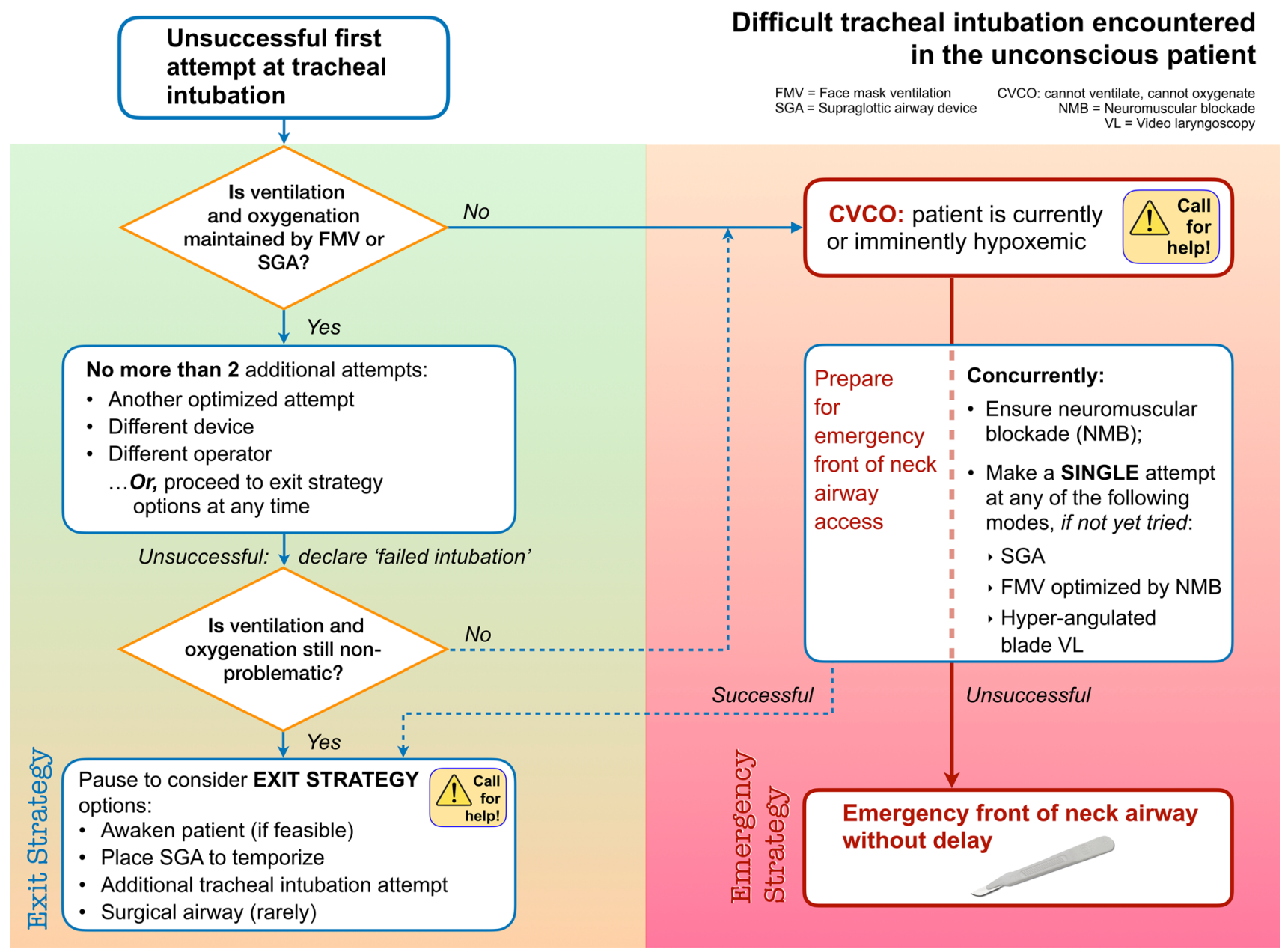

FIGURE Flow diagram: difficult tracheal intubation encountered in the unconscious patient

- Placement of an SGA. A number of reports have indicated that an attempt at SGA placement was often overlooked prior to performing eFONA., ${ }^{3,68}$

- Two-handed FMV with an oropharyngeal airway, facilitated by neuromuscular blockade.

- Video laryngoscopic tracheal intubation, if not already attempted. The CAFG is of the opinion that an attempt at tracheal intubation facilitated by HA-VL should ideally have occurred prior to eFONA. Notwithstanding, in an already hypoxemic patient, this option implies that the video laryngoscope is already present, so that the attempt will not substantively delay the onset of eFONA, if unsuccessful.

If adequate oxygenation is restored with any of the foregoing, eFONA is not immediately required and the airway manager can now consider exit strategy options (FIGURE). Conversely, if the foregoing options have failed, then eFONA should proceed without delay (see next section).
The ASA Closed Claims ${ }^{1}$ and NAP4 ${ }^{3}$ studies describe airway manager delay in the recognition of an evolving CVCO emergency as a major contributor to brain damage and death. While some CVCO situations may be immediately evident (e.g., cannot ventilate, currently hypoxemic), others may occur over time, making their recognition more challenging for those managing the patient ("change blindness"). ${ }^{200,201}$ Thus, all team members should be explicitly empowered to say when they believe a trigger for declaring a CVCO situation has occurred. Multidisciplinary simulation exercises can help identify and break down barriers to having any team member speak up in such situations. ${ }^{202,203}$ Although infrequent, CVCO emergencies are often unanticipated and can occur in otherwise healthy patients (e.g., those presenting for elective surgery). Therefore, all airway managers should regularly practice their skills in eFONA to maintain competence in the procedure. 


\subsection{Emergency FONA}

While surgeons familiar with the technique may prefer to perform rapid tracheotomy in the CVCO situation, ${ }^{204}$ in the hands of non-surgeon clinicians, and because of anatomic advantages in adult patients, eFONA should generally proceed via the cricothyroid space. For its simplicity, ease of equipment stocking, generalizability to different airway manager types, and emerging evidence of first-pass success in various settings, ${ }^{205,206}$ the CAFG recommends a scalpelbougie-tube approach for cricothyrotomy. If feasible, the neck should be fully extended. The location of the cricothyroid membrane (CTM) itself may be difficult to identify by external palpation in some patients, ${ }^{207}$ so the CAFG recommends beginning cricothyrotomy with an initial 4-6 cm longitudinal incision over the estimated location of the midline of the larynx in all adult patients. Identifying the laryngeal cartilage and its midline may be aided by a "laryngeal handshake" (i.e., moving the laryngeal cartilage from side to side while attempting to palpate the cricothyroid space). ${ }^{208}$ Following the longitudinal incision, re-palpation within the wound will allow more accurate identification of the CTM. A transverse incision is made through the CTM, then access to the opened trachea is maintained with the airway manager's finger or the scalpel blade turned into a cephalad-caudad orientation. The bougie is passed into the trachea behind the placeholder finger or alongside the blade, then with finger or blade removed, a 6.0-mm internal diameter cuffed tube (adult patient) is advanced over the bougie. The cuff is inflated and correct tube location confirmed. The CAFG recommends stocking the following equipment at every airway management location: disposable scalpel (\#10, 20, or 21 blade), a bougie, and a 6.0 tracheal tube (for adult hospitals), all packaged together. Size-based pediatric equipment should be readily available in pediatric facilities. Pediatric eFONA options are discussed in section 11.6.

False passage of a bougie or tracheal tube can occur during cricothyrotomy or tracheotomy, so correct tube placement must be confirmed by waveform capnography. A flat trace should be considered to represent a malpositioned tracheal tube until proven otherwise and must not be attributed to hypoxemic cardiac arrest. ${ }^{3,209}$

\section{Supraglottic airway use as the intended technique}

Similar considerations to those appearing in section 7 on tracheal intubation apply to the use of an SGA as the intended airway management technique.
8.1 Unsuccessful first attempt at SGA use with $\mathrm{SpO}_{2}$ in a safe range

If SGA placement and ventilation is unsuccessful on the first attempt, provided patient oxygenation remains nonproblematic, the following recommendations apply:

- Further attempts at SGA insertion can be made but should involve doing something different than what has already failed. Troubleshooting options for further attempts appear in Table 5. Ventilation through a successfully placed SGA is likely optimized with the head and neck in a neutral position. ${ }^{210}$

- Multiple SGA insertion attempts also involve the potential for trauma; $;^{38,166}$ although less data underscores the recommendation, attempts at SGA insertion should be limited.

- After a maximum of three unsuccessful SGA attempts, SGA failure should be declared, and the airway manager should move to SGA exit strategy options. Exit strategy options might be considered after fewer attempts when SGA failure has occurred after failed tracheal intubation.

8.2 Exit strategy options after failed SGA use, with $\mathrm{SpO}_{2}$ in a safe range

Once a failed SGA situation has been determined and declared, provided patient ventilation and oxygenation remain non-problematic with FMV, the following exit strategy options can be considered:

- Proceed with tracheal intubation: Proceeding with tracheal intubation is often prudent after the failure of SGA placement or use. If not already administered during SGA troubleshooting, laryngoscopy and intubation should be facilitated by NMB.

- Temporize, or proceed with FMV: As long as it remains effective, FMV can be maintained pending the preparation of additional equipment (e.g., for tracheal intubation), arrival of additional expertise, or until the patient's emergence from general anesthesia. Alternatively, a short surgical case could be completed with FMV, if appropriate. Attention should be directed towards maximizing upper airway patency during FMV and minimizing delivery airway pressure, to help limit gastric insufflation.

- Awakening the patient: As with failed tracheal intubation, awakening the patient is an option after failed SGA use in the adequately oxygenated patient. This option is especially recommended if tracheal intubation is anticipated to be difficult or suspected trauma had already occurred with SGA insertion 
attempts. Conversely, when intended SGA use fails in the arrested or critically ill patient, awakening the patient will not be an option - temporizing with FMV, tracheal intubation or, rarely, FONA will be the only available exit strategies.

\subsection{Failed SGA use with current or imminent hypoxemia}

When SGA ventilation has failed, if both tracheal intubation and FMV are also unsuccessful, then a CVCO situation exists. Neuromuscular blockade should be ensured. Management of the CVCO situation should proceed according to the foregoing description in sections 7.4 and 7.5.

\section{Confirmation of tracheal intubation and continuous waveform capnography}

The CAFG advocates continuous waveform capnography as the gold standard for confirming correct tracheal tube placement. Waveform capnography has excellent sensitivity and specificity (Table 10) and is widely available. Pattern recognition of capnographic waveforms can easily be learned. ${ }^{211}$ For tracheal intubation by nasal, oral or front-of-neck routes, assessment of multiple sustained amplitude waveforms ${ }^{212}$ are required to conclude the tracheal tube is correctly positioned and to avoid false positive results (e.g., $\mathrm{CO}_{2}$ detection with esophageal intubation).

Waveform capnography should also be routinely used to confirm effective ventilation by face-mask ${ }^{15,71}$ or SGA. ${ }^{213}$ Capnography will generally provide earlier feedback on their effectiveness than changes in $\mathrm{SpO}_{2}$.

Effectiveness of chest compressions as well as return of spontaneous circulation during cardiopulmonary resuscitation can also be assessed using waveform capnography. The 2015 American Heart Association guidelines for cardiopulmonary resuscitation in adults recommends waveform capnography as "the most reliable method of confirming and monitoring correct placement of an ETT" during cardiac arrest. ${ }^{214}$ After cardiac arrest, $\mathrm{CO}_{2}$ detectable by waveform capnography is likely to persist for at least $30 \mathrm{~min},{ }^{215}$ although the waveform will be attenuated. In this context, a flat capnograph must not be ascribed to the absence of pulmonary perfusion-rather, esophageal intubation or false passage must be excluded ("no trace $=$ wrong place"). ${ }^{209}$

Colorimetric capnometry is less specific than waveform capnography, with additional causes of a false positive result (Table 10). It may have a role if waveform capnography is not available. Other modes of tracheal tube confirmation together with their potential pitfalls, sensitivities, and specificities are presented in Table 10.

The CAFG recommends the routine use of waveform capnography with at least one other method to confirm successful tracheal intubation. To help direct the airway manager's attention to the need for objective confirmation, we recommend routinely making a verbal declaration such as "sustained $\mathrm{CO}_{2}$ confirmed" or "good trace, right place" once success has been determined. ${ }^{209,216}$ Finally, the CAFG recommends ongoing waveform capnography monitoring in all intubated patients, in all hospital locations, including within-hospital transportation.

\section{The obstetric patient-special considerations}

Many studies continue to indicate a higher risk of failed tracheal intubation in the parturient than in the general surgical population, ${ }^{35,37,51,249,250}$ although this has been challenged by other studies. ${ }^{36,251}$ Regardless, other patient and contextual factors amplify difficulty. The parturient can be physiologically unforgiving, the need for out-ofhours emergency work common, and the obstetrical suite can be isolated from access to difficult airway equipment or additional expertise.

Obstetrical suites should be well-equipped with difficult airway equipment including, but not limited to, secondgeneration SGAs, video laryngoscopes, a FB, and equipment for cricothyrotomy. ${ }^{181}$ As rates of regional anesthesia for $\mathrm{CD}$ continue to be high, ${ }^{36,252}$ trainees and attending staff with significant exposure to obstetrical practice must make the effort to attain and maintain competence in difficult airway techniques.

Antenatal airway screening of all obstetrical patients should ideally occur with multidisciplinary consultation when indicated. ${ }^{253,254}$ Should a parturient possess a nonreassuring airway, early epidural catheter placement and testing should occur during labour. If $\mathrm{CD}$ under general anesthesia is required, the airway should be re-assessed, recognizing the dynamic nature of the airway during labour. ${ }^{253,255}$ Landmarking neck anatomy including the cricothyroid space by external palpation is particularly challenging in this population; ultrasound has proven useful. $^{256,257}$

For CD under general anesthesia, the patient should be positioned optimally and pre-oxygenation undertaken with a tightly fitting face mask with a standard flow of $15 \mathrm{~L}$ $\min ^{-1}$. Evidence for the benefit of high-flow nasal oxygen (HFNO) therapy for the obstetric patient is mixed. It is less effective than a tightly applied face mask for preoxygenation $^{258-260}$ but may provide benefit during 
Table 10 Modes of confirmation of tracheal intubation, with test sensitivities, specificities and select causes of false negative and false positive results

\section{Confirmation of tracheal intubation}

$\begin{array}{cll}\text { Colorimetric } & 97-100 \% \text { (non- arrest) }^{220,223-225} & 91-100 \% \text { (non-arrest) }^{220,223,224} \\ \text { capnometry } & 69-85 \% \text { (arrest) }^{223,225,226} & 100 \%(\text { arrest })^{223,226}\end{array}$

\begin{tabular}{|c|c|c|}
\hline $\begin{array}{l}\text { Visualization of } \\
\text { tracheal tube } \\
\text { between } \\
\text { cords }\end{array}$ & No data & No data \\
\hline $\begin{array}{l}\text { Endoscopic } \\
\text { visualization } \\
\text { of trachea } \\
\text { through } \\
\text { tracheal tube }\end{array}$ & No data & No data \\
\hline Ultrasound & $92-99 \%^{233-236}$ & $93-100 \%^{233-236}$ \\
\hline Auscultation & $70-100 \% \%^{217-219,221,237,238}$ & $50-95 \%^{217-219,221,237,238}$ \\
\hline
\end{tabular}

Published specificity range, if available (percentage of esophageal intubations correctly identified by a negative test result)

Waveform $\quad 98-100 \%$ (non-arrest) $^{212,217-223}$ capnography $68 \%$ (arrest) $^{217}$ $100 \%$ (arrest) $^{217}$

Esophageal
$\begin{aligned} & \text { detector } \\ & \text { device }\end{aligned}$

\section{Select causes of a false negative Sele} result (tube is in trachea, but a negative test result suggests it is in the esophagus)

- Equipment malfunction or disconnect

- Severe bronchospasm

- Kinked or occluded tube

- Tracheal obstruction

- Tracheal tube cuff not inflated

- Obstruction of pulmonary circulation

As above, plus:

- Low cardiac output/severe hypotension

- $\mathrm{ETCO}_{2}<2-5 \%$

- Neonates and infants 227

- Adverse patient anatomy precludes a view of any aspect of the larynx during DL or Mac-VL

- Visualization obscured by blood, secretions or aspirated gastric contents

- Scope fogging

- Image misinterpretation by inexperienced clinician

- Poor quality stethoscope

- Noisy environment

- Thick chest \& abdominal walls

- Severe bronchospasm

- Obesity (BMI > 35)

- Parturients at induction of general anesthesia

- $<10 \mathrm{~kg}$

- Bronchospasm; mainstem intubation

- Tube occluded by pulmonary edema, mucus plug or blood

Tube misting $100 \%^{237,247,248} \quad 15-71 \%^{237,247,248}$
No data lect causes of a false positive result (tube is in esophagus or pharynx, but a positive test result suggests it is in the trachea)

- Failure to assess for sustained waveforms

- Tube lying in pharynx outside larynx (e.g., cuff above the cords)

- Recent extensive use of FMV or bilevel positive airway pressure non-invasive ventilation ${ }^{222}$

- Ingestion of antacid or carbonated beverages

As above, plus:

- Contamination of detector with acidic gastric contents; ${ }^{228}$

- Recent instillation of medications through the tracheal tube including epinephrine, atropine, surfactant, ${ }^{229}$ naloxone.

- "Glottic impersonation": entrance to hypopharynx is misinterpreted as the larynx during excess lifting pressure on laryngoscope ${ }^{230}$

- Inadvertent intubation of a tracheoesophageal fisutla ${ }^{231,232}$

No data 
subsequent laryngoscopy. ${ }^{181}$ The CAFG recommends the primary use of VL to facilitate tracheal intubation of the parturient.

\subsection{Unsuccessful first attempt at tracheal intubation in the parturient}

An unsuccessful optimized attempt at tracheal intubation in the parturient should be transitioned rapidly to FMV or SGA insertion. Help should be enlisted. Cricoid pressure should be released if thought to be contributing to difficulty. If face-mask- or SGA ventilation is successful and adequate patient oxygenation is maintained, a second attempt at tracheal intubation can be made with a different device or by a more experienced airway manager. The use of VL has been reported to be effective after failed DL in the parturient. ${ }^{37,262}$ If the second attempt is unsuccessful, a failed tracheal intubation situation should be declared and exit strategy options considered. This is one fewer attempt than might be considered for the non-parturient, reflecting the parturient's adverse physiology.

10.2 Failed tracheal intubation in the parturient with $\mathrm{SpO}_{2}$ in a safe range-exit strategy options

Having verbally declared the failed intubation situation, the airway manager should maintain oxygenation by facemask- or SGA ventilation while considering exit strategy options. Help should be sought, if available. Further actions are predicated on the status of the mother and the fetus.

- No fetal or maternal distress: If the situation is stable without maternal or fetal emergency, the mother can be allowed to emerge from general anesthesia. Once awake, use of regional anesthesia can be revisited if not contraindicated, or awake tracheal intubation can be performed.

- Fetal or maternal distress exists: If the situation is unstable with either fetal or maternal emergency, an SGA should be placed (if not already done) to enable $\mathrm{CD}$ or maternal resuscitation to proceed. Cricoid pressure should be released. For $\mathrm{CD}$ while using an SGA, a generous surgical incision should be made, minimal fundal pressure applied, and vacuum extraction considered, as necessary. ${ }^{263}$ Early use of an SGA in a rescue scenario is accepted practice in the parturient, with success rates reported to be between 86 and $100 \% .^{37,51,250}$ In a review of 45 years of obstetric airway management in the United Kingdom, there was a steady, decade-over-decade increase in continuing with CD using SGAs after failed tracheal intubation, coinciding with their increasing use as rescue devices. ${ }^{51}$ A second-generation SGA with an esophageal drainage port should be used, optimally incorporating a widediameter conduit to support FB-aided tracheal intubation, if chosen. When feasible, a suction catheter can be advanced down the drainage port to help drain the esophagus of any gastric contents. The catheter should be removed after suctioning is completed.

Once the fetus has been delivered or the maternal emergency stabilized, whether to complete the case using the SGA or to secure the airway by tracheal intubation before proceeding should be based on the context of the patient's body mass index, fasting status, and predicted surgical complexity and duration. Currently, there is no evidence to support or refute continuing with the case with a well-functioning SGA. Use of an SGA to complete CD after failed tracheal intubation is supported by studies of the elective use of SGAs for CD under general anesthesia rather than tracheal intubation. Most such studies originate from outside North America, in countries where general anesthesia is more commonly used for $\mathrm{CD}$ and the population may be of lower average body mass index. ${ }^{58-60,264}$ With most using second-generation SGAs, the studies indicate a high success rate and minimal occurrence of gastric content aspiration. ${ }^{265}$ Notwithstanding, the CAFG does not currently espouse SGA use for elective $\mathrm{CD}$. This position might change as the role of ultrasound in assessing gastric contents and aspiration risk becomes more understood. ${ }^{265}$

\section{3 "Cannot ventilate, cannot oxygenate" in the parturient}

The CVCO scenario in the parturient is also defined as failed tracheal intubation not rescued by attempts at both face-mask- or SGA ventilation, with current or imminent hypoxemia. Maternal oxygen desaturation is likely to occur rapidly, leading to fetal compromise and precluding maternal emergence from general anesthesia. Thus, cricothyrotomy must occur without delay. Once correct placement of a cuffed tracheal tube placed via cricothyrotomy is confirmed, $\mathrm{CD}$ can proceed.

\subsection{Tracheal extubation and the postpartum period}

Maternal mortality data from both the USA and UK indicate that many of the reported obstetric-related airway catastrophes occurred during the postpartum period-i.e., at emergence after $\mathrm{CD}$, in the postanesthesia care unit, or during postpartum surgical procedures (e.g., postpartum hemorrhage). ${ }^{266,267}$ Vigilance during these phases is thus paramount. 


\section{The pediatric patient-special considerations}

Respiratory events are the most common cause of adverse events during pediatric anesthesia. ${ }^{268}$ These complications are age dependent, with neonates and infants being at highest risk. Elective management of patients $<12$ months of age with a known or suspected difficult airway should occur in a specialized centre, when feasible. ${ }^{269}$

Young children are predisposed to adverse respiratory events during airway management because of their high metabolic demand and relatively small respiratory reserve. Resulting short apnea times can lead to hypoxemia, bradycardia, and cardiac arrest. ${ }^{39}$ Supplementary oxygen before and during tracheal intubation is recommended to reduce the risk of hypoxemia. Options include $\mathrm{HFNO}^{270}$ or oxygen applied buccally, via a laryngoscope, or through an advancing tracheal tube.

Airway assessment tools have not been validated in small children, but micrognathia, microstomia, macroglossia, and evidence of temporomandibular joint dysfunction are suggestive of airway management difficulty. Asthma, wheezing, upper respiratory tract infections, snoring, and smoking exposure are associated with critical respiratory events regardless of the airway device used.

\subsection{Pediatric airway obstruction}

Help should be summoned and poor head/neck position, nasal/oral obstruction, secretions, foreign material, atelectasis, and gastric distension should be considered and treated promptly. Pharmacologic treatment should be employed for laryngospasm, bronchospasm, opioidmediated rigidity, and light anesthesia.

\subsection{Pediatric FMV}

The incidence of difficult FMV (albeit with varying definitions) in children has been reported to be between 6.6 and $9.5 \% .^{25,26}$ Impossible FMV is less common, with only six occurrences reported in 1,018 pediatric difficult intubation registry cases. ${ }^{39}$

\subsection{Pediatric SGAs}

Pediatric SGAs have significantly improved in recent years. ${ }^{271}$ Fewer adverse respiratory events have been described with SGA use for infant airway management compared with tracheal intubation. Neonatal resuscitation with SGAs can result in fewer neonatal intensive care unit admissions and superior resuscitation rates compared with FMV and tracheal intubation.

\subsection{Pediatric flexible bronchoscopy through a conduit}

Performing FB intubation through an SGA is particularly useful for difficult infant airways, compared with VL. ${ }^{272}$ Supraglottic airways for this purpose should have a wide inlet, a short ventilation tube and should facilitate a good bronchoscopic view of the glottis. They should also allow for easy withdrawal of the SGA. The air-Q ILA ${ }^{\mathrm{TM}}$, (Cookgas ${ }^{\circledR}$ LLC, Mercury Medical, Clearwater, FL, USA) has shown comparatively higher airway leak pressures and superior flexible bronchoscopic views of the glottis than the LMA Unique (Teleflex, Inc., Wayne, PA, USA) in pediatric patients. ${ }^{273}$

\subsection{Pediatric tracheal intubation}

In a multicentre pediatric difficult intubation registry, easy tracheal intubation by an anesthesiologist occurred in up to $99.8 \%$ of pediatric cases. ${ }^{39}$ Of the remaining cases that proved difficult, $20 \%$ had an airway-related complication. Risk factors for complications included $\geq$ two intubation attempts, weight $<2 \mathrm{~kg}$, a short thyromental distance, and multiple DL attempts. ${ }^{39}$ The CAFG recommends limiting DL attempts to two and rapidly transitioning to a FB or VL. When used after failed DL, a FB was successful in 54\% of cases and VL succeeded in 55\%. Cuffed tracheal tubes are recommended for all children $>3 \mathrm{~kg}$, with appropriate care to avoid cuff overinflation. ${ }^{274}$

\subsection{Pediatric eFONA}

Employing eFONA through the CTM in a neonate or infant is not feasible or recommended. At this age, the CTM is underdeveloped and difficult to landmark; the cartilages are also fragile and susceptible to injury. An open tracheotomy is preferred if an individual with the skills is present. Needle tracheotomy is an alternative, although one animal study suggests a low success rate and significant risk of tracheal compression by the advancing needle. ${ }^{275}$ If needle cricothyrotomy is used, ventilation should ideally proceed using a Ventrain device (Ventinova Medical, Eindhoven, Netherlands) ${ }^{276,277}$ For older children (i.e., $>8-12$ yr), the scalpel-bougie technique can be used via the CTM. There is no evidence that cricothyrotomy kits are superior to a scalpel cricothyrotomy technique.

\section{Tracheal extubation of the at-risk airway}

Tracheal extubation is an elective procedure and is addressed further in the companion article ${ }^{8}$. 


\section{Human factors in airway management}

The term "difficult airway" typically relates to patient anatomy or physiology that adversely affects ease of airway management. Difficulty can also arise from how an airway manager and the assembled team performs during challenging airway management. This can sometimes be impacted by suboptimal organizational culture. Human factor issues have been reported to be contributory in $40-100 \%$ of airway management-related adverse outcomes. ${ }^{1,278}$

Many human factor issues occurring during airway management relate to dysfunctional team dynamics. These are characterized by poor communication, inadequate leadership, and the lack of a shared mental model. ${ }^{279}$ In situ multidisciplinary training improves team dynamics but is still not commonly done. ${ }^{280}$ Checklists can improve communication, help ensure equipment availability, and aid in team briefing. ${ }^{281-283}$ While the published evidence for tracheal intubation checklists has not shown decreased mortality, outcomes such as hypoxemia may be reduced. ${ }^{284}$

Human factor issues that may impact airway management and their potential mitigation strategies are presented in Table 11. The published evidence base regarding these factors continues to evolve.

\section{Airway leads and quality assurance}

The CAFG recommends designating an individual as departmental or hospital "airway lead" to help adopt or develop difficult airway protocols, recommend difficult airway equipment, and ensure equipment standardization across hospital locations. ${ }^{3,288}$ The airway lead or a multidisciplinary airway committee can also help organize training events and assist in airway-related quality assurance by debriefing critical incidents or nearevents. Debriefing can provide opportunities to share concerns but also to help reinforce what went well. It is important that such quality assurance occurs using an objective "just culture" model, focusing more on organizational learning and less on the role of any one individual in the event.

\section{Documentation}

All airway management events should be documented in the patient's paper or electronic medical record (EMR). Previously documented difficult or failed tracheal intubation is a robust predictor of subsequent difficulty. ${ }^{289}$ In general, the airway technique used should be recorded, together with optimizing maneuvers or adjuncts used, view obtained, number of attempts, details of any challenges encountered as well as how they were resolved. Major (e.g., significant hypoxemia, hypotension, cardiac arrest) and minor (e.g., mucosal bleeding, dental injury) complications should be recorded. Suggestions for future airway management should also be recorded.

If performed, ease of FMV must always be recorded (e.g., with a mandatory field in an EMR). This is crucial information to help guide future planning for airway management.

The airway manager should personally inform the patient after a significantly difficult airway encounter and provide a written letter describing the difficulty and how it was resolved. Copies of the letter should be added to the patient's medical record and forwarded to the patient's primary care physician. The patient should be flagged as having a potentially difficult airway during subsequent hospital admissions, including use of in-hospital alert bracelets. Difficult airway information should also be submitted to local or national difficult airway databases, if available (e.g., www.medicalert.org/everybody/difficultairwayintubation-registry). In addition, using a robust incident reporting system will help address system-wide patient safety and quality of care issues. ${ }^{290}$

In the future, it may be possible to routinely add photos or recordings of VL to the EMR, or for the patient to use secure, app-based technology to store or access their own airway-related information. ${ }^{291}$

\section{Airway management education}

Routine clinical practice may not be sufficient to maintain airway management skills. Performing a scalpel-bougie aided cricothyrotomy in a CVCO situation is a rare, yet high acuity event. Successfully performing such infrequently used skills requires deliberate practice, characterized by regular learning opportunities in a simulation environment that incorporates clear goals, focuses on technique, and provides timely expert feedback. ${ }^{292-295}$ This option is safe for the learner, teacher, and patient. Mistakes can be corrected through coaching, and procedures can be simulated repetitively and interrupted for immediate feedback. As competence and comfort with a skill such as cricothyrotomy increases, the airway manager is more likely to consider its use as part of a plan rather than symbolic of a failure of the plan.

Valuable lessons in airway management can also occur through experiential learning in the OR. Nevertheless, the experience that develops over years is not necessarily equivalent to expertise. Expertise is gained by exposure to difficult airways, with learners pushing themselves to manage increasingly difficult experiences. ${ }^{294}$ Learning is 
Table 11 Human factor-related issues in airway management, with potential mitigating strategies

Potential human factor-related issues that may occur during management of the difficult airway in the unconscious patient, with mitigation strategies

Issue

Possible mitigation strategies:

by the airway manager

by the assembled team

by the organization

Calling for help: The airway manager might overlook calling for help when difficulty occurs.

- Have personal triggers for calling for help, e.g., (1) whenever you first contemplate it; (2) failed intubation or failed SGA insertion after a maximum of 3 attempts or (3) a CVCO situation.

- Recognize that a helper can provide hands for tasks, so that the airway manager can concentrate on the "big picture" and reduce their stress level.

- Consider making a habit of asking a colleague to physically stand by when inducing a patient with anticipated airway risk.

Loss of "situation awareness." During an airway crisis, it can be difficult to correctly receive and process incoming information. This will impair diagnosis and decision-making and may promote inappropriate fixation on a single familiar but ineffective technique (perseveration). ${ }^{285}$

- Maintaining situation awareness involves long-term memory content, which may be difficult to access during a critical event. Help from other staff provides the airway manager with additional processing capacity for integration of basic information. ${ }^{285,286}$

- Call for help after 3 failed attempts at the intended technique: a fresh pair of eyes will help interrupt perseveration. Be alert for the "change blindness" 200,201 that can occur when a critical airway event evolves over time. A newly arrived helper may better be able to see the obvious.

- Use difficult airway techniques in dayto-day routine practice (e.g., the combination of $\mathrm{VL}$ and $\mathrm{FB}$ ) so that their use is practiced, and so that you think of them when in difficulty.

Fear. Faced with a hypoxemic patient, the • Call for help early in any evolving airway manager might experience a maladaptive sympathetic response. This might include fight (e.g., arguing with team members); flight (e.g. disbelief of patient vital signs) or freeze (e.g., not performing eFONA when indicated) airway event. Not being emotionally invested, a newly arrived colleague might possess better situation awareness.

- Have a strategy (a coordinated series of patients, whether predicted or not. Moving smoothly and deliberately through the steps of a pre-planned strategy will help keep you in contro of yourself as well as the situation. Mentally rehearse the strategy on a regular basis.

Barriers to use of eFONA can include not - By training in eFONA, all airway knowing which procedure to employ ("device confusion"), lack of confidence in one's ability to perform the procedure, or a "freeze" response to fear. The reluctance to act may manifest by insisting a surgeon or better qualified person be called to perform eFONA. managers must be prepared to proceed with eFONA themselves.
- Deliberately practice eFONA on a parttask trainer at least twice a year.

- When encountering difficulty, follow the department's recommended algorithm or cognitive aid. plans) for encountering difficulty in all

- Strongly consider physically attending any request for backup, even if phrased as a "heads-up".

- A helper should announce their arrival by asking "How can I help?"

- Any team member should be empowered to call for help, bring in equipment, or call a code blue independently.

- Perform a team briefing before embarking on all airway management. Include specific mention of triggers for moving from one plan to the next and empower all team members to speak up once they feel a trigger has occurred.

- Team members should be trained in the interpretation of waveform capnography and pulse oximetry and should be empowered to declare when waveform capnography is nonreassuring or the $\mathrm{SpO}_{2}$ is decreasing.

- Ensure all team members have been empowered to suggest using an SGA for rescue or CVCO at any time and that they know the equipment's location.

- During an airway crisis, team members must recognize that the airway manager who induced the patient is deeply emotionally invested. They might be experiencing a profound sympathetic response, compromising thinking or motor skills. Any team member should call for help if they feel it is in the best interest of the patient.

- Once qualified help arrives, the initial airway manager should consider moving to a supportive role on the team, providing information and suggestions.

- Team performance in rare emergencies such as CVCO benefits from in situ simulation.

- Swapping team roles during simulation sessions may reveal latent errors in communication and equipment.
- All departments should foster a culture of calling for help.

- During team training, e.g., during in situ simulation sessions, requesting help should always be debriefed as a critical action.

- Mandate adherence to a standard operating procedure for the difficult airway by using an algorithm or cognitive aid based on the algorithm.

- Facilitate multidisciplinary in situ team simulation to practice using the algorithm or cognitive aid for difficult airway scenarios. A major objective during such sessions is to encourage and empower all team members to speak up.

- Airway workshops should include education on non-technical as well as technical skills. Common cognitive errors should be addressed.
- High acuity but rare events such as CVCO should be "overlearned" during simulation sessions. ${ }^{286}$ This will help demystify them and make their management more routine in clinicians' minds.
- The organization should ensure that all airway managers are trained in and prepared to perform eFONA.

- Minimize choices to a single technique for high-stress procedures such as eFONA (e.g., scalpel-bougie-tube for the adult patient).

- Make task trainers easily accessible for individual clinician eFONA practice. This can include 3D-printed models of the larynx. 
Table 11 continued



$\mathrm{CRM}=$ crisis resource management $\mathrm{CVCO}=$ "cannot ventilate, cannot oxygenate"; eFONA = emergency front of neck airway access; FB = flexible bronchoscope; $\mathrm{SGA}=$ supraglottic airway; $\mathrm{SpO}_{2}=$ peripheral oxygen saturation by pulse oximetry; VL = video laryngoscopy

optimally achieved by assessing the trainee's background knowledge and skill before starting in the OR, establishing educational goals, and supervising performance with immediate feedback. ${ }^{296}$ Thus, a knowledgeable teacher can optimize learning for trainees in the OR. ${ }^{297,298}$ Making educational programs multidisciplinary can further augment benefit by creating positive relationships between disciplines.

\section{Summary and key recommendations}

As the literature on airway management evolves, guidelines and recommendations must be updated regularly. ${ }^{299}$ Published national airway management guidelines espouse largely consistent management principles. This invites an opportunity to develop a universal lexicon of terms to describe common airway management situations ${ }^{300}$ and accepted principles on how to manage them. ${ }^{301}$ When such universal guidance is published, it must still be applied to the national or local context in which the airway manager practices. In this third iteration of airway management recommendations from the
CAFG, there are few guiding principles and recommendations:

- Resources allowing, VL, with appropriately selected blade type, should be used for the first attempt at tracheal intubation.

- Multiple attempts at tracheal intubation and even SGA insertion are associated with adverse events; firstattempt success should be a goal.

- If unsuccessful on the first attempt, further attempts can be made at the intended technique provided patient ventilation and oxygenation are maintained. A stepwise progression through different optimizing maneuvers, devices, or airway managers should occur.

- Total attempts at the intended technique should be limited to three or fewer before pausing to consider exit strategy options. Patient ventilation and oxygenation should be maintained while considering and then executing the exit strategy.

- Exit strategy options to consider after declaring failed tracheal intubation include awakening the patient, temporizing with an SGA, proceeding with one further controlled attempt at tracheal intubation with a different technique, or FONA. 
- A CVCO situation is defined by the failure of tracheal intubation, FMV, and SGA use, with imminent or current hypoxemia. Neuromuscular blockade should be ensured, and eFONA undertaken in a timely fashion.

- The CAFG recommends that a scalpel-bougie-tube technique be used for adult eFONA, and that the necessary equipment for eFONA, packaged together, be stocked at every hospital airway management location.

- Similar principles are broadly applicable to the parturient and to the pediatric patient.

- Human factors often contribute to airway-related adverse events; efforts should be made to educate airway managers about common pitfalls.

- An airway lead is recommended for all hospitals to help many aspects of airway management at an organizational level.

Without doubt, no matter how well addressed, it will always be preferable to avoid having to manage a difficult airway presenting in the unconscious patient. To this end, thorough patient airway evaluation should be made, followed by appropriate decision-making and safe implementation of the plan. These aspects of safe management of a patient with a difficult airway are addressed further in the companion article ${ }^{8}$, as is advice on tracheal extubation of the difficult airway patient.

Author contributions See Appendix.

Acknowledgements The members of the CAFG thank Brooke Ballantyne Scott, MLIS for invaluable assistance in conducting literature searches for this project. In addition, we wish to express our gratitude to the following clinicians for their helpful review of this manuscript and thoughtful suggestions: Drs. Loes Bruijstens, Tim Cook, Thomas Heidegger, Michael Kristensen, Michael Murphy and Arnim Vlatten

Disclosures See Appendix.

Funding None.

Editorial responsibility This submission was handled by Hilary P. Grocott, former Editor-in-Chief, Canadian Journal of Anesthesia/ Journal canadien d'anesthésie.

Open Access This article is licensed under a Creative Commons Attribution-NonCommercial 4.0 International License, which permits any non-commercial use, sharing, adaptation, distribution and reproduction in any medium or format, as long as you give appropriate credit to the original author(s) and the source, provide a link to the Creative Commons licence, and indicate if changes were made. The images or other third party material in this article are included in the article's Creative Commons licence, unless indicated otherwise in a credit line to the material. If material is not included in the article's Creative Commons licence and your intended use is not permitted by statutory regulation or exceeds the permitted use, you will need to obtain permission directly from the copyright holder. To view a copy of this licence, visit http://creativecommons.org/licenses/by-nc/4.0/.
Appendix: Author contributions and disclosures

\begin{tabular}{|c|c|c|}
\hline Author & Contribution(s) & Disclosure(s) \\
\hline $\begin{array}{l}\text { J. Adam } \\
\text { Law, MD }\end{array}$ & $\begin{array}{l}\text { Focus Group chair; data } \\
\text { acquisition, analysis, and } \\
\text { interpretation; writing } \\
\text { and critically revising } \\
\text { article; final approval of } \\
\text { version to be published. }\end{array}$ & $\begin{array}{l}\text { Work supported by the } \\
\text { Department of } \\
\text { Anesthesia, Dalhousie } \\
\text { University. } \\
\text { Course co-director of } \\
\text { Airway Interventions } \\
\text { and Management in } \\
\text { Emergencies (AIME) } \\
\text { course and partner in } \\
\text { parent company } \\
\text { AIME Training Inc. } \\
\text { Course director of the } \\
\text { Anesthesia edition of } \\
\text { the Difficult Airway } \\
\text { Course and partner in } \\
\text { parent company } \\
\text { Airway Management } \\
\text { Education Center, } \\
\text { LLC. } \\
\text { Recipient of equipment } \\
\text { as loan or donation } \\
\text { from Verathon, } \\
\text { Ambu, Karl Storz and } \\
\text { Covidien. }\end{array}$ \\
\hline $\begin{array}{l}\text { Laura } \\
\text { Duggan, } \\
\text { MD }\end{array}$ & $\begin{array}{l}\text { Data acquisition, analysis, } \\
\text { and interpretation; } \\
\text { critically revising article; } \\
\text { final approval of version } \\
\text { to be published. }\end{array}$ & $\begin{array}{l}\text { Editor of the journal } \\
\text { Anaesthesia and co- } \\
\text { creator of The Airway } \\
\text { App }\end{array}$ \\
\hline $\begin{array}{l}\text { Mathieu } \\
\text { Asselin, } \\
\text { MD }\end{array}$ & $\begin{array}{l}\text { Data acquisition, analysis, } \\
\text { and interpretation; } \\
\text { writing and critically } \\
\text { revising article; final } \\
\text { approval of version to be } \\
\text { published. }\end{array}$ & None \\
\hline $\begin{array}{l}\text { Paul Baker, } \\
\text { MBChB, } \\
\text { MD }\end{array}$ & $\begin{array}{l}\text { Data acquisition, analysis, } \\
\text { and interpretation; } \\
\text { critically revising article; } \\
\text { final approval of version } \\
\text { to be published. }\end{array}$ & $\begin{array}{l}\text { Co-owner and inventor, } \\
\text { the ORSIM } \\
\text { bronchoscopy } \\
\text { simulator. Owner of } \\
\text { the AirwaySkills } \\
\text { course and recipient of } \\
\text { equipment as loan or } \\
\text { donation from Fisher } \\
\text { and Paykel } \\
\text { Healthcare, Karl } \\
\text { Storz, Verathon, } \\
\text { Ambu, Covidien, } \\
\text { Truphatec, AAM } \\
\text { Healthcare, Welch } \\
\text { Allyn }\end{array}$ \\
\hline $\begin{array}{l}\text { Edward } \\
\text { Crosby, } \\
\text { MD }\end{array}$ & $\begin{array}{l}\text { Data acquisition, analysis, } \\
\text { and interpretation; } \\
\text { writing and critically } \\
\text { revising article; final } \\
\text { approval of version to be } \\
\text { published. }\end{array}$ & None \\
\hline
\end{tabular}




\begin{tabular}{|c|c|c|}
\hline Author & Contribution(s) & Disclosure(s) \\
\hline $\begin{array}{l}\text { Andrew } \\
\text { Downey, } \\
\text { MBBS }\end{array}$ & $\begin{array}{l}\text { Data acquisition, analysis, } \\
\text { and interpretation; } \\
\text { critically revising article; } \\
\text { final approval of version } \\
\text { to be published. }\end{array}$ & None \\
\hline $\begin{array}{l}\text { Orlando R. } \\
\text { Hung, MD }\end{array}$ & $\begin{array}{l}\text { Data acquisition, analysis, } \\
\text { and interpretation; } \\
\text { critically revising article; } \\
\text { final approval of version } \\
\text { to be published. }\end{array}$ & $\begin{array}{l}\text { Holds a US patent of a } \\
\text { Light-guided Tracheal } \\
\text { Intubation Device. } \\
\text { Co-authored a textbook: } \\
\text { Management of the } \\
\text { Difficult and Failed } \\
\text { Airway. }\end{array}$ \\
\hline $\begin{array}{l}\text { Philip M. } \\
\text { Jones, } \\
\text { MD, MSc }\end{array}$ & $\begin{array}{l}\text { Data acquisition, analysis, } \\
\text { and interpretation; } \\
\text { critically revising article; } \\
\text { final approval of version } \\
\text { to be published. }\end{array}$ & $\begin{array}{l}\text { No industry conflicts to } \\
\text { declare. } \\
\text { Dr Jones is Deputy } \\
\text { Editor-in-Chief of the } \\
\text { Canadian Journal of } \\
\text { Anesthesia. }\end{array}$ \\
\hline $\begin{array}{l}\text { George } \\
\text { Kovacs, } \\
\text { MD, } \\
\text { MHPE }\end{array}$ & $\begin{array}{l}\text { Data acquisition, analysis, } \\
\text { and interpretation; } \\
\text { critically revising article; } \\
\text { final approval of version } \\
\text { to be published. }\end{array}$ & $\begin{array}{l}\text { Work supported by the } \\
\text { Department of } \\
\text { Emergency Medicine, } \\
\text { Dalhousie University. } \\
\text { Course co-director of } \\
\text { Airway Interventions } \\
\text { and Management in } \\
\text { Emergencies (AIME) } \\
\text { course and partner in } \\
\text { parent company } \\
\text { AIME Training Inc. } \\
\text { Recipient of } \\
\text { equipment as loan or } \\
\text { donation from } \\
\text { Verathon, Ambu, Kar } \\
\text { Storz and Covidien. }\end{array}$ \\
\hline $\begin{array}{l}\text { François } \\
\quad \text { Lemay, } \\
\text { MD }\end{array}$ & $\begin{array}{l}\text { Data acquisition, analysis, } \\
\text { and interpretation; } \\
\text { critically revising article; } \\
\text { final approval of version } \\
\text { to be published. }\end{array}$ & None \\
\hline $\begin{array}{l}\text { Rudiger } \\
\text { Noppens, } \\
\text { MD PhD }\end{array}$ & $\begin{array}{l}\text { Data acquisition, analysis, } \\
\text { and interpretation; } \\
\text { critically revising article; } \\
\text { final approval of version } \\
\text { to be published. }\end{array}$ & $\begin{array}{l}\text { Recipient of equipment } \\
\text { for clinical trial from } \\
\text { Karl Storz, Germany. } \\
\text { Recipient of honoraria } \\
\text { from Medtronic and } \\
\text { Karl Storz for lectures } \\
\text { at Euroanesthesia. }\end{array}$ \\
\hline $\begin{array}{l}\text { Matteo } \\
\text { Parotto, } \\
\text { MD, PhD }\end{array}$ & $\begin{array}{l}\text { Data acquisition, analysis, } \\
\text { and interpretation; } \\
\text { writing and critically } \\
\text { revising article; final } \\
\text { approval of version to be } \\
\text { published. }\end{array}$ & $\begin{array}{l}\text { Supported by an Early } \\
\text { Investigator Award } \\
\text { from the Department } \\
\text { of Anesthesiology and } \\
\text { Pain Medicine, } \\
\text { University of Toronto } \\
\text { and Toronto General } \\
\text { Hospital }\end{array}$ \\
\hline $\begin{array}{l}\text { Roanne } \\
\text { Preston, } \\
\text { MD }\end{array}$ & $\begin{array}{l}\text { Data acquisition, analysis, } \\
\text { and interpretation; } \\
\text { critically revising article; } \\
\text { final approval of version } \\
\text { to be published. }\end{array}$ & None \\
\hline
\end{tabular}

\begin{tabular}{|c|c|c|}
\hline Author & Contribution(s) & Disclosure(s) \\
\hline $\begin{array}{l}\text { Nick Sowers, } \\
\text { MD }\end{array}$ & $\begin{array}{l}\text { Data acquisition, analysis, } \\
\text { and interpretation; } \\
\text { critically revising article; } \\
\text { final approval of version } \\
\text { to be published. }\end{array}$ & None \\
\hline $\begin{array}{l}\text { Kathryn } \\
\text { Sparrow, } \\
\text { MD, } \\
\text { MScHQ }\end{array}$ & $\begin{array}{l}\text { Data acquisition, analysis, } \\
\text { and interpretation; } \\
\text { writing and critically } \\
\text { revising article; final } \\
\text { approval of version to be } \\
\text { published. }\end{array}$ & $\begin{array}{l}\text { Received one prior } \\
\text { honorarium for } \\
\text { attending an expert } \\
\text { input forum from } \\
\text { Merck Canada Inc. As } \\
\text { an instructor and } \\
\text { course faculty } \\
\text { member, she has } \\
\text { received honoraria } \\
\text { from Airway } \\
\text { Interventions and } \\
\text { Management in } \\
\text { Emergencies (AIME), } \\
\text { The Difficult Airway } \\
\text { Course, and Heart and } \\
\text { Stroke Foundation of } \\
\text { Canada. }\end{array}$ \\
\hline $\begin{array}{l}\text { Timothy P. } \\
\text { Turkstra, } \\
\text { MD, } \\
\text { MEng }\end{array}$ & $\begin{array}{l}\text { Data acquisition, analysis, } \\
\text { and interpretation; } \\
\text { writing and critically } \\
\text { revising article; final } \\
\text { approval of version to be } \\
\text { published. }\end{array}$ & None \\
\hline $\begin{array}{l}\text { David T. } \\
\text { Wong, } \\
\text { MD }\end{array}$ & $\begin{array}{l}\text { Data acquisition, analysis, } \\
\text { and interpretation; } \\
\text { critically revising article; } \\
\text { final approval of version } \\
\text { to be published. }\end{array}$ & $\begin{array}{l}\text { Board of Directors, } \\
\text { Society for Airway } \\
\text { Management }\end{array}$ \\
\hline
\end{tabular}

\section{References}

1. Joffe AM, Aziz MF, Posner KL, Duggan LV, Mincer SL, Domino $K B$. Management of difficult tracheal intubation: a closed claims analysis. Anesthesiology 2019; 131: 818-29.

2. Crosby ET, Duggan LV, Finestone PJ, Liu R, De Gorter R, Calder LA. Anesthesiology airway-related medicolegal cases from the Canadian Medical Protection Association. Can J Anesth 2021; 68: 183-95.

3. Cook T, Woodall N, Frerk C. 4th National Audit Project of the Royal College of Anaesthetists and the Difficult Airway Society. Major complications of airway management in the United Kingdom. London: The Royal College of Anaesthetists; 2011.

4. Kluger MT, Culwick MD, Moore MR, Merry AF. Aspiration during anaesthesia in the first 4000 incidents reported to webAIRS. Anaesth Intensive Care 2019; 47: 442-51.

5. Crosby ET, Cooper RM, Douglas MJ, et al. The unanticipated difficult airway with recommendations for management. Can J Anaesth 1998; 45: 757-76.

6. Law JA, Broemling N, Cooper RM, et al. The difficult airway with recommendations for management-part 1-difficult tracheal intubation encountered in an unconscious/induced patient. Can J Anesth 2013; 60: 1089-118. 
7. Law JA, Broemling N, Cooper RM, et al. The difficult airway with recommendations for management-part 2-the anticipated difficult airway. Can J Anesth 2013; 60: 1119-38.

8. Law JA, Duggan LV, Asselin M, et al. Canadian Airway Focus Group consensus-based recommendations for management of the difficult airway: part 2. Planning and implementing safe management of the patient with an anticipated difficult airway Can J Anesth 2021; DOI: https://doi.org/10.1007/s12630-02102008-z.

9. Frerk C, Mitchell VS, McNarry AF, et al. Difficult Airway Society 2015 guidelines for management of unanticipated difficult intubation in adults. Br J Anaesth 2015; 115: 827-48.

10. Higgs A, McGrath BA, Goddard C, et al. Guidelines for the management of tracheal intubation in critically ill adults. $\mathrm{Br} \mathrm{J}$ Anaesth 2018; 120: 323-52.

11. Piepho T, Cavus E, Noppens $R$, et al. $\mathrm{S} 1$ guidelines on airway management: guideline of the German Society of Anesthesiology and Intensive Care Medicine. Anaesthesist 2015; 64(Suppl 1): 27-40.

12. Myatra SN, Shah A, Kundra P, et al. All India Difficult Airway Association 2016 guidelines for the management of unanticipated difficult tracheal intubation in adults. Indian $\mathbf{J}$ Anaesth 2016; 60: 885-98.

13. Cook TM. Strategies for the prevention of airway complications - a narrative review. Anaesthesia 2018; 73: 93-111.

14. Han $R$, Tremper $K K$, Kheterpal $S$, $O^{\prime}$ Reilly $M$. Grading scale for mask ventilation. Anesthesiology 2004; DOI: https://doi.org/10. 1097/00000542-200407000-00059.

15. Lim KS, Nielsen JR. Objective description of mask ventilation. Br J Anaesth 2016; 117: 828-9.

16. Cormack RS, Lehane J. Difficult tracheal intubation in obstetrics. Anaesthesia 1984; 39: 1105-11.

17. Yentis SM, Lee DJ. Evaluation of an improved scoring system for the grading of direct laryngoscopy. Anaesthesia 1998; 53: 1041-4.

18. Cook TM. A new practical classification of laryngeal view. Anaesthesia 2000; 55: 274-9.

19. Norskov AK, Wetterslev J, Rosenstock CV, et al. Prediction of difficult mask ventilation using a systematic assessment of risk factors vs. existing practice - a cluster randomised clinical trial in 94,006 patients. Anaesthesia 2017; 72: 296-308.

20. Norskov AK, Rosenstock CV, Wetterslev J, Astrup G, Afshari A, Lundstrom LH. Diagnostic accuracy of anaesthesiologists' prediction of difficult airway management in daily clinical practice: a cohort study of 188064 patients registered in the Danish Anaesthesia Database. Anaesthesia 2015; 70: 272-81.

21. Kheterpal $S$, Han $R$, Tremper KK, et al. Incidence and predictors of difficult and impossible mask ventilation. Anesthesiology 2006; 105: 885-91.

22. Kheterpal $S$, Healy D, Aziz MF, et al. Incidence, predictors, and outcome of difficult mask ventilation combined with difficult laryngoscopy: a report from the multicenter perioperative outcomes group. Anesthesiology 2013; 119: 1360-9.

23. Aziz MF, Kim D, Mako J, Hand K, Brambrink AM. A retrospective study of the performance of video laryngoscopy in an obstetric unit. Anesth Analg 2012; 115: 904-6.

24. Hawthorne L, Wilson R, Lyons $G$, Dresner M. Failed intubation revisited: 17-yr experience in a teaching maternity unit. Br J Anaesth 1996; 76: 680-4.

25. Valois-Gomez T, Oofuvong M, Auer G, Coffin D, Loetwirivakul $W$, Correa JA. Incidence of difficult bag-mask ventilation in children: a prospective observational study. Paediatr Anaesth 2013; 23: 920-6.

26. Daigle CH, Fiadjoe JE, Laverriere EK, et al. Difficult bag-mask ventilation in critically ill children is independently associated with adverse events. Crit Care Med 2020; 48: e744-52.
27. Alkhouri H, Vassiliadis $J$, Murray M, et al. Emergency airway management in Australian and New Zealand emergency departments: a multicentre descriptive study of 3710 emergency intubations. Emerg Med Australas 2017; 29: 499-508.

28. De Jong A, Molinari N, Terzi N, et al. Early identification of patients at risk for difficult intubation in the intensive care unit: development and validation of the MACOCHA score in a multicenter cohort study. Am J Respir Crit Care Med 2013; 187: 832-9.

29. Kheterpal S, Martin L, Shanks AM, Tremper KK. Prediction and outcomes of impossible mask ventilation: a review of 50,000 anesthetics. Anesthesiology 2009; 110: 891-7.

30. Muller JU, Semmel T, Stepan R, et al. The use of the laryngeal tube disposable by paramedics during out-of-hospital cardiac arrest: a prospectively observational study (2008-2012). Emerg Med J 2013; 30: 1012-6.

31. Jabre P, Penaloza A, Pinero D, et al. Effect of bag-mask ventilation vs endotracheal intubation during cardiopulmonary resuscitation on neurological outcome after out-of-hospital cardiorespiratory arrest: a randomized clinical trial. JAMA 2018; 319: 779-87.

32. Heinrich S, Birkholz T, Irouschek A, Ackermann A, Schmidt J. Incidences and predictors of difficult laryngoscopy in adult patients undergoing general anesthesia: a single-center analysis of 102,305 cases. J Anesth 2013; 27: 815-21.

33. De Jong A, Molinari N, Pouzeratte $Y$, et al. Difficult intubation in obese patients: incidence, risk factors, and complications in the operating theatre and in intensive care units. $\mathrm{Br} \mathbf{J}$ Anaesth 2015; 114: 297-306.

34. Heinrich S, Irouschek A, Prottengeier J, Ackermann A, Schmidt $J$. Adverse airway events in parturient compared with nonparturient patients. Is there a difference? Results from a quality management project. J Obstet Gynaecol Res 2015; 41: 1032-9.

35. Rajagopalan S, Suresh M, Clark SL, Serratos B, Chandrasekhar $S$. Airway management for cesarean delivery performed under general anesthesia. Int J Obstet Anesth 2017; 29: 64-9.

36. McKeen DM, George RB, O'Connell CM, et al. Difficult and failed intubation: incident rates and maternal, obstetrical, and anesthetic predictors. Can J Anesth 2011; 58: 514-24.

37. Odor PM, Bampoe S, Moonesinghe SR, et al. General anaesthetic and airway management practice for obstetric surgery in England: a prospective, multicentre observational study. Anaesthesia 2021; 76: 460-71.

38. Engelhardt T, Virag $K$, Veyckemans $F$, Habre W; APRICOT Group of the European Society of Anaesthesiology Clinical Trial Network. Airway management in paediatric anaesthesia in Europe-insights from APRICOT (Anaesthesia Practice In Children Observational Trial): a prospective multicentre observational study in 261 hospitals in Europe. Br J Anaesth 2018; 121: 66-75.

39. Fiadjoe JE, Nishisaki A, Jagannathan $N$, et al. Airway management complications in children with difficult tracheal intubation from the Pediatric Difficult Intubation (PeDI) registry: a prospective cohort analysis. Lancet Respir Med 2016; 4: 37-48.

40. Driver BE, Prekker ME, Klein LR, et al. Effect of use of a bougie vs endotracheal tube and stylet on first-attempt intubation success among patients with difficult airways undergoing emergency intubation: a randomized clinical trial. JAMA 2018; 319: 2179-89.

41. Sakles JC, Douglas MJ, Hypes CD, Patanwala AE, Mosier JM. Management of patients with predicted difficult airways in an academic emergency department. J Emerg Med 2017; 53: 163-71.

42. Goto Y, Goto T, Hagiwara Y, Tsugawa $Y$, et al. Techniques and outcomes of emergency airway management in Japan: an 
analysis of two multicentre prospective observational studies, 2010-2016. Resuscitation 2017; 114: 14-20.

43. Hasegawa $K$, Shigemitsu K, Hagiwara $Y$, et al. Association between repeated intubation attempts and adverse events in emergency departments: an analysis of a multicenter prospective observational study. Ann Emerg Med 2012; 60: 749-54.e2.

44. Kerslake D, Oglesby AJ, Di Rollo N, et al. Tracheal intubation in an urban emergency department in Scotland: a prospective, observational study of 3738 intubations. Resuscitation 2015; 89: 20-4.

45. Heuer JF, Barwing TA, Barwing J, et al. Incidence of difficult intubation in intensive care patients: analysis of contributing factors. Anaesth Intensive Care 2012; 40: 120-7.

46. Smischney NJ, Seisa MO, Heise KJ, et al. Practice of intubation of the critically ill at Mayo Clinic. J Intensive Care Med 2017; DOI: https://doi.org/10.1177/0885066617691495.

47. Semler MW, Janz DR, Russell DW, et al. A multicenter, randomized trial of ramped position vs sniffing position during endotracheal intubation of critically ill adults. Chest 2017; 152 : $712-22$.

48. Aziz MF, Brambrink AM, Healy DW, et al. Success of intubation rescue techniques after failed direct laryngoscopy in adults: a retrospective comparative analysis from the Multicenter Perioperative Outcomes Group. Anesthesiology 2016; 125: 656-66.

49. Schroeder RA, Pollard R, Dhakal I, et al. Temporal trends in difficult and failed tracheal intubation in a regional community anesthetic practice. Anesthesiology 2018; 128: 502-10.

50. Madsen $M G$, Lundstrom $L H$, Rosenstock $C V$. Failed intubation in obstetrics registered in the Danish anaesthesia database. Acta Anaesthesiol Scand 2013; 57: 36 (abstract).

51. Kinsella SM, Winton AL, Mushambi MC, et al. Failed tracheal intubation during obstetric general anaesthesia: a literature review. Int J Obstet Anesth 2015; 24: 356-74.

52. Bhattacharjee $S$, Maitra $S$, Baidya DK. A comparison between video laryngoscopy and direct laryngoscopy for endotracheal intubation in the emergency department: a meta-analysis of randomized controlled trials. J Clin Anesth 2018; 47: 21-6.

53. Lockey D, Crewdson K, Weaver A, Davies G. Observational study of the success rates of intubation and failed intubation airway rescue techniques in 7256 attempted intubations of trauma patients by pre-hospital physicians. Br J Anaesth 2014; 113: 220-5.

54. Park L, Zeng I, Brainard A. Systematic review and metaanalysis of first-pass success rates in emergency department intubation: creating a benchmark for emergency airway care. Emerg Med Australas 2017; 29: 40-7.

55. Pallin DJ, Dwyer RC, Walls RM, Brown CA $3^{\text {rd }}$; NEAR III Investigators. Techniques and trends, success rates, and adverse events in emergency department pediatric intubations: a report from the National Emergency Airway Registry. Ann Emerg Med 2016; 67: 610-15.e1.

56. Ono Y, Kakamu T, Kikuchi H, Mori Y, Watanabe Y, Shinohara $K$. Expert-performed endotracheal intubation-related complications in trauma patients: incidence, possible risk factors, and outcomes in the prehospital setting and emergency department. Emerg Med Int 2018; DOI: https://doi.org/10.1155/ 2018/5649476.

57. Ramachandran SK, Mathis MR, Tremper KK, Shanks AM, Kheterpal S. Predictors and clinical outcomes from failed laryngeal mask airway Unique ${ }^{\mathrm{TM}}$ : a study of 15,795 patients. Anesthesiology 2012; 116: 1217-26.

58. Geng ZY, Wang DX. Laryngeal mask airway for cesarean delivery: a 5-year retrospective cohort study. Chin Med J (Engl) 2017; 130: 404-8.

59. Yao WY, Li SY, Yuan YJ, et al. Comparison of Supreme laryngeal mask airway versus endotracheal intubation for airway management during general anesthesia for cesarean section: a randomized controlled trial. BMC Anesthesiol 2019; DOI: https://doi.org/10.1186/s12871-019-0792-9.

60. Li SY, Yao WY, Yuan YJ, et al. Supreme ${ }^{\mathrm{TM}}$ laryngeal mask airway use in general anesthesia for category 2 and 3 cesarean delivery: a prospective cohort study. BMC Anesthesiol 2017; DOI: https://doi.org/10.1186/s12871-017-0460-x.

61. St. Clair Logan A, Morris P. Complications following use of the laryngeal mask airway in children. Paediatr Anaesth 1993; 3: 297-300.

62. Gahan K, Studnek JR, Vandeventer S. King LT-D use by urban basic life support first responders as the primary airway device for out-of-hospital cardiac arrest. Resuscitation 2011; 82: 1525-8.

63. Saito T, Liu $W$, Chew ST, Ti LK. Incidence of and risk factors for difficult ventilation via a supraglottic airway device in a population of 14,480 patients from South-East Asia. Anaesthesia 2015; 70: 1079-83.

64. Mathis MR, Haydar B, Taylor EL, et al. Failure of the laryngeal mask airway Unique ${ }^{\mathrm{TM}}$ and Classic ${ }^{\mathrm{TM}}$ in the pediatric surgical patient: a study of clinical predictors and outcomes. Anesthesiology 2013; 119: 1284-95.

65. Benger JR, Kirby K, Black $S$, et al. Effect of a strategy of a supraglottic airway device vs tracheal intubation during out-ofhospital cardiac arrest on functional outcome: the AIRWAYS-2 randomized clinical trial. JAMA 2018; 320: 779-91.

66. Diggs LA, Yusuf JE, De Leo G. An update on out-of-hospital airway management practices in the United States. Resuscitation 2014; 85: 885-92.

67. Bernhard M, Gries A, Ramshorn-Zimmer A, Wenzel V, Hossfeld $B$. Insertion success of the laryngeal tube in emergency airway management. Biomed Res Int 2016; DOI: https://doi.org/10. $1155 / 2016 / 3619159$

68. Rosenstock CV, Norskov AK, Wetterslev J, Lundstrom LH; Danish Anaesthesia Database. Emergency surgical airway management in Denmark: a cohort study of 452461 patients registered in the Danish Anaesthesia Database. Br J Anaesth 2016; 117 Suppl 1: i75-82.

69. Kwon YS, Lee CA, Park S, Ha SO, Sim YS, Baek MS. Incidence and outcomes of cricothyrotomy in the "cannot intubate, cannot oxygenate" situation. Medicine (Baltimore) 2019; DOI: https:// doi.org/10.1097/MD.0000000000017713.

70. Peters J, Bruijstens L, van der Ploeg J, Tan E, Hoogerwerf N, Edwards $M$. Indications and results of emergency surgical airways performed by a physician-staffed helicopter emergency service. Injury 2015; 46: 787-90.

71. Japanese Society of Anesthesiologists. JSA airway management guideline 2014: to improve the safety of induction of anesthesia. J Anesth 2014; 28: 482-93.

72. Fei M, Blair JL, Rice MJ, et al. Comparison of effectiveness of two commonly used two-handed mask ventilation techniques on unconscious apnoeic obese adults. Br J Anaesth 2017; 118: 618-24.

73. Sato $S$, Hasegawa $M$, Okuyama $M$, et al. Mask ventilation during induction of general anesthesia: influences of obstructive sleep apnea. Anesthesiology 2017; 126: 28-38.

74. Joffe AM, Hetzel S, Liew EC. A two-handed jaw-thrust technique is superior to the one-handed "EC-clamp" technique for mask ventilation in the apneic unconscious person. Anesthesiology 2010; 113: 873-9.

75. Bouvet L, Albert ML, Augris $C$, et al. Real-time detection of gastric insufflation related to facemask pressure-controlled ventilation using ultrasonography of the antrum and epigastric auscultation in nonparalyzed patients: a prospective, randomized, double-blind study. Anesthesiology 2014; 120: 326-34. 
76. Gerstein NS, Carey MC, Braude DA, et al. Efficacy of facemask ventilation techniques in novice providers. J Clin Anesth 2013; 25: 193-7.

77. Warters RD, Szabo TA, Spinale FG, DeSantis SM, Reves JG. The effect of neuromuscular blockade on mask ventilation. Anaesthesia 2011; 66: 163-7.

78. Itagaki T, Oto J, Burns SM, Jiang Y, Kacmarek RM, Mountjoy $J R$. The effect of head rotation on efficiency of face mask ventilation in anaesthetised apnoeic adults: a randomised, crossover study. Eur J Anaesthesiol 2017; 34: 432-40.

79. Joshi S, Prakash S, Mullick P, Usha G, Pawar M. Clinical evaluation of the cricoid pressure effect on bag mask ventilation, Proseal laryngeal mask airway placement and ventilation. Turk $\mathbf{J}$ Anaesthesiol Reanim 2018; 46: 381-7.

80. Gruber E, Oberhammer R, Balkenhol K, et al. Basic life support trained nurses ventilate more efficiently with laryngeal mask supreme than with facemask or laryngeal tube suctiondisposable-a prospective, randomized clinical trial. Resuscitation 2014; 85: 499-502.

81. Cook TM, Kelly FE. Time to abandon the 'vintage' laryngeal mask airway and adopt second-generation supraglottic airway devices as first choice. Br J Anaesth 2015; 115: 497-9.

82. Intersurgical. User guide: i-gel ${ }^{\circledR}$ single use supraglottic airway. Available from URL: https://www.intersurgical.com/products/ airway-management/i-gel-supraglottic-airway\#downloads (accessed March 2021).

83. The Laryngeal Mask Company Limited. Instructions for use LMA Classic Excel ${ }^{\mathrm{TM}}$. Available from URL: http://www.lmacoifu.com/sites/default/files/node/1898/ifu/revision/2921/ paa2100001c.pdf (accessed March 2021).

84. Dhulkhed PV, Khyadi SV, Jamale PB, Dhulkhed VK. A prospective randomised clinical trial for the comparison of two techniques for the insertion of Proseal laryngeal mask airway in adults-index finger insertion technique versus $90^{\circ}$ rotation technique. Turk J Anaesthesiol Reanim 2017; 45: 98-102.

85. Park JH, Lee JS, Nam SB, Ju JW, Kim MS. Standard versus rotation technique for insertion of supraglottic airway devices: systematic review and meta-analysis. Yonsei Med J 2016; 57: 987-97.

86. Yun MJ, Hwang $J W$, Park $S H$, et al. The $90^{\circ}$ rotation technique improves the ease of insertion of the ProSeal ${ }^{\mathrm{TM}}$ laryngeal mask airway in children. Can J Anesth 2011; 58: 379-83.

87. Jeon YT, Na HS, Park SH, et al. Insertion of the ProSeal laryngeal mask airway is more successful with the $90^{\circ}$ rotation technique. Can J Anesth 2010; 57: 211-5.

88. Vannucci A, Rossi IT, Prifti $K$, et al. Modifiable and nonmodifiable factors associated with perioperative failure of extraglottic airway devices. Anesth Analg 2018; 126: 1959-67.

89. Van Zundert AA, Gatt SP, Kumar CM, Van Zundert TC. Visionguided placement of supraglottic airway device prevents airway obstruction: a prospective audit. Br J Anaesth 2017; 118: 462-3.

90. Van Zundert AA, Kumar CM, Van Zundert TC. Malpositioning of supraglottic airway devices: preventive and corrective strategies. Br J Anaesth 2016; 116: 579-82.

91. Li CW, Xue FS, Xu YC, et al. Cricoid pressure impedes insertion of, and ventilation through, the ProSeal laryngeal mask airway in anesthetized, paralyzed patients. Anesth Analg 2007; 104: 1195-8.

92. Asai T, Goy RW, Liu EH. Cricoid pressure prevents placement of the laryngeal tube and laryngeal tube-suction II. Br J Anaesth 2007; 99: 282-5.

93. Hashimoto Y, Asai T, Arai T, Okuda Y. Effect of cricoid pressure on placement of the I-gel ${ }^{\mathrm{TM}}$ : a randomised study. Anaesthesia 2014; 69: 878-82.

94. Aghamohammadi D, Eydi $M$, Hosseinzadeh H, Amiri Rahimi M, Golzari SE. Assessment of mini-dose succinylcholine effect on facilitatinglaryngeal mask airway insertion. J Cardiovasc Thorac Res 2013; 5: 17-21.

95. Na HS, Jeon YT, Shin HJ, Oh AY, Park HP, Hwang JW. Effect of paralysis at the time of ProSeal laryngeal mask airway insertion on pharyngolaryngeal morbidities. A randomized trial. PLoS One 2015; DOI: https://doi.org/10.1371/journal.pone. 0134130.

96. Hattori K, Komasawa N, Miyazaki Y, Kido H, Deguchi S, Minami T. Muscle relaxant facilitates i-gel insertion by novice doctors: a prospective randomized controlled trial. J Clin Anesth 2016; 33: 218-22.

97. Fujiwara A, Komasawa N, Nishihara I, et al. Muscle relaxant effects on insertion efficacy of the laryngeal mask ProSeal((R)) in anesthetized patients: a prospective randomized controlled trial. J Anesth 2015; 29: 580-4.

98. Kim GW, Kim JY, Kim SJ, Moon YR, Park EJ, Park SY. Conditions for laryngeal mask airway placement in terms of oropharyngeal leak pressure: a comparison between blind insertion and laryngoscope-guided insertion. BMC Anesthesiol 2019; DOI: https://doi.org/10.1186/s12871-018-0674-6.

99. van Zundert AA, Wyssusek KH, Pelecanos A, Roets M, Kumar $C M$. A prospective randomized comparison of airway seal using the novel vision-guided insertion of LMA-Supreme(R) and LMA-Protector(R). J Clin Monit Comput 2020; 34: 285-94.

100. Choo CY, Koay CK, Yoong CS. A randomised controlled trial comparing two insertion techniques for the Laryngeal Mask Airway Flexible $\mathrm{T}^{\mathrm{TM}}$ in patients undergoing dental surgery. Anaesthesia 2012; 67: 986-90.

101. Ozgul U, Erdil FA, Erdogan MA, et al. Comparison of videolaryngoscope-guided versus standard digital insertion techniques of the ProSeal ${ }^{\mathrm{TM}}$ laryngeal mask airway: a prospective randomized study. BMC Anesthesiol 2019; DOI: https://doi.org/10.1186/s12871-019-0915-3.

102. Miyazaki Y, Komasawa N, Matsunami S, Kusaka Y, Minami T. Laryngoscopy facilitates successful i-gel insertion by novice doctors: a prospective randomized controlled trial. J Anesth 2015; 29: 654-9.

103. Taneja S, Agarwalt M, Dali JS, Agrawal G. Ease of Proseal laryngeal mask airway insertion and its fibreoptic view after placement using gum elastic bougie: a comparison with conventional techniques. Anaesth Intensive Care 2009; 37: 435-40.

104. Joffe AM, Schroeder KM, Shepler JA, Galgon RE. Validation of the unassisted, gum-elastic bougie-guided, laryngeal mask airway-ProSeal $^{\mathrm{TM}}$ placement technique in anaesthetized patients. Indian J Anaesth 2012; 56: 255-8.

105. Aziz MF, Dillman D, Fu R, Brambrink AM. Comparative effectiveness of the C-MAC video laryngoscope versus direct laryngoscopy in the setting of the predicted difficult airway. Anesthesiology 2012; 116: 629-36.

106. Piepho T, Fortmueller K, Heid FM, Schmidtmann I, Werner C, Noppens RR. Performance of the C-MAC video laryngoscope in patients after a limited glottic view using Macintosh laryngoscopy. Anaesthesia 2011; 66: 1101-5.

107. Gaszynski T. Clinical experience with the C-Mac videolaryngoscope in morbidly obese patients. Anaesthesiol Intensive Ther 2014; 46: 14-6.

108. Kaplan MB, Hagberg CA, Ward DS, et al. Comparison of direct and video-assisted views of the larynx during routine intubation. J Clin Anesth 2006; 18: 357-62.

109. Byhahn C, Iber T, Zacharowski K, et al. Tracheal intubation using the mobile C-MAC video laryngoscope or direct laryngoscopy for patients with a simulated difficult airway. Minerva Anestesiol 2010; 76: 577-83.

110. Raimann FJ, Dietze PE, Cuca CE, et al. Prospective trial to compare direct and indirect laryngoscopy using C-MAC 
$\mathrm{PM}(\mathrm{R})$ with Macintosh Blade and $\mathrm{D}-\mathrm{Blade}(\mathrm{R})$ in a simulated difficult airway. Emerg Med Int 2019; DOI: https://doi.org/10. $1155 / 2019 / 1067473$.

111. Hossfeld B, Frey K, Doerges V, Lampl L, Helm M. Improvement in glottic visualisation by using the C-MAC PM video laryngoscope as a first-line device for out-of-hospital emergency tracheal intubation: an observational study. Eur $\mathbf{J}$ Anaesthesiol 2015; 32: 425-31.

112. Malpas $G$, Kovacs $G$, Mackinnon SP, Hung O, Phipps $S$, Law $J A$. The videoscopic view may not be significantly superior to the directly sighted peroral view during Macintosh-style videolaryngoscopy: a randomized equivalence cadaver trial. Can J Anesth 2020; 67: 827-35.

113. Brown CA 3rd, Kaji AH, Fantegrossi A, et al. Video laryngoscopy compared to augmented direct laryngoscopy in adult emergency department tracheal intubations: a National Emergency Airway Registry (NEAR) Study. Acad Emerg Med 2020; DOI: https://doi.org/10.1111/acem.13851.

114. Sakles JC, Mosier J, Chiu S, Cosentino M, Kalin L. A comparison of the C-MAC video laryngoscope to the Macintosh direct laryngoscope for intubation in the emergency department. Ann Emerg Med 2012; 60: 739-48.

115. Yi IK, Kwak HJ, Kim KM, Ahn SH, Lee SY, Kim JY. Comparison of Pentax Airway Scope and Macintosh laryngoscope for orotracheal intubation in children: a randomised noninferiority trial. Acta Anaesthesiol Scand 2019; 63: 853-8.

116. Serocki G, Neumann T, Scharf E, Dorges V, Cavus E. Indirect videolaryngoscopy with C-MAC D-Blade and GlideScope: a randomized, controlled comparison in patients with suspected difficult airways. Minerva Anestesiol 2013; 79: 121-9.

117. Serocki G, Bein B, Scholz J, Dorges V. Management of the predicted difficult airway: a comparison of conventional blade laryngoscopy with video-assisted blade laryngoscopy and the GlideScope. Eur J Anaesthesiol 2010; 27: 24-30.

118. Turkstra TP, Harle CC, Armstrong KP, et al. The GlideScopespecific rigid stylet and standard malleable stylet are equally effective for GlideScope use. Can J Anesth 2007; 54: 891-6.

119. Hoshijima $H$, Mihara $T$, Maruyama $K$, et al. McGrath videolaryngoscope versus Macintosh laryngoscope for tracheal intubation: a systematic review and meta-analysis with trial sequential analysis. J Clin Anesth 2018; 46: 25-32.

120. Abdelgadir IS, Phillips RS, Singh D, Moncreiff MP, Lumsden $J L$. Videolaryngoscopy versus direct laryngoscopy for tracheal intubation in children (excluding neonates). Cochrane Database Syst Rev 2017; DOI: https://doi.org/10.1002/14651858. CD011413.pub2.

121. Cooper RM, Pacey JA, Bishop MJ, McCluskey SA. Early clinical experience with a new videolaryngoscope (GlideScope) in 728 patients. Can J Anesth 2005; 52: 191-8.

122. Aziz MF, Healy D, Kheterpal S, Fu RF, Dillman D, Brambrink $A M$. Routine clinical practice effectiveness of the Glidescope in difficult airway management: an analysis of 2,004 Glidescope intubations, complications, and failures from two institutions. Anesthesiology 2011; 114: 34-41.

123. Greer D, Marshall KE, Bevans S, Standlee A, McAdams P, Harsha $W$. Review of videolaryngoscopy pharyngeal wall injuries. Laryngoscope 2017; 127: 349-53.

124. Pham $Q$, Lentner $M, H u$ A. Soft palate injuries during orotracheal intubation with the videolaryngoscope. Ann Otol Rhinol Laryngol 2017; 126: 132-7.

125. De Jong A, Pouzeratte $Y$, Laplace A, et al. Macintosh videolaryngoscope for intubation in the operating room: a comparative quality improvement project. Anesth Analg 2021; 132: 524-35.

126. Gudivada KK, Jonnavithula N, Pasupuleti SL, Apparasu CP, Ayya SS, Ramachandran $G$. Comparison of ease of intubation in sniffing position and further neck flexion. J Anaesthesiol Clin Pharmacol 2017; 33: 342-7.

127. Lebowitz PW, Shay H, Straker T, Rubin D, Bodner S. Shoulder and head elevation improves laryngoscopic view for tracheal intubation in nonobese as well as obese individuals. J Clin Anesth 2012; 24: 104-8.

128. El-Orbany MI, Getachew YB, Joseph NJ, Salem MR, Friedman $M$. Head elevation improves laryngeal exposure with direct laryngoscopy. J Clin Anesth 2015; 27: 153-8.

129. Akihisa $Y$, Hoshijima H, Maruyama K, Koyama $Y$, Andoh $T$. Effects of sniffing position for tracheal intubation: a metaanalysis of randomized controlled trials. Am J Emerg Med 2015; 33: 1606-11.

130. Levitan RM, Kinkle WC, Levin WJ, Everett $W W$. Laryngeal view during laryngoscopy: a randomized trial comparing cricoid pressure, backward-upward-rightward pressure, and bimanual laryngoscopy. Ann Emerg Med 2006; 47: 548-55.

131. Amathieu R, Combes X, Abdi W, et al. An algorithm for difficult airway management, modified for modern optical devices (Airtraq laryngoscope; LMA CTrach ${ }^{\mathrm{TM}}$ ): a 2-year prospective validation in patients for elective abdominal, gynecologic, and thyroid surgery. Anesthesiology 2011; 114: 25-33.

132. Gu Y, Robert J, Kovacs $G$, et al. A deliberately restricted laryngeal view with the GlideScope ${ }^{\circledR}$ video laryngoscope is associated with faster and easier tracheal intubation when compared with a full glottic view: a randomized clinical trial. Can J Anesth 2016; 63: 928-37.

133. Dupanovic M, Isaacson SA, Borovcanin Z, et al. Clinical comparison of two stylet angles for orotracheal intubation with the GlideScope video laryngoscope. J Clin Anesth 2010; 22: 352-9.

134. Jones PM, Turkstra TP, Armstrong KP, et al. Effect of stylet angulation and endotracheal tube camber on time to intubation with the GlideScope. Can J Anesth 2007; 54: 21-7.

135. Reynolds EC, Crowther $N$, Corbett L, et al. Improving laryngoscopy technique and success with the C-MAC(R) D blade: development and dissemination of the 'Bath C-MAC D blade guide'. Br J Anaesth 2020; 125: e162-4.

136. Turkstra TP, Cusano F, Fridfinnson JA, Batohi P, Rachinsky M. Early endotracheal tube insertion with the GlideScope: a randomized controlled trial. Anesth Analg 2016; 122: 753-7.

137. Turkstra TP, Turkstra DC, Pavlosky AW, Jones PM. Simultaneous en bloc endotracheal tube insertion with GlideScope ${ }^{\circledR}$ Titanium ${ }^{\mathrm{TM}}$ video laryngoscope use: a randomized-controlled trial. Can J Anesth 2020; 67: 1515-23.

138. Arima T, Nagata $O$, Miura $T$, et al. Comparative analysis of airway scope and Macintosh laryngoscope for intubation primarily for cardiac arrest in prehospital setting. Am J Emerg Med 2014; 32: 40-3.

139. Aziz MF, Abrons RO, Cattano D, et al. First-attempt intubation success of video laryngoscopy in patients with anticipated difficult direct laryngoscopy: a multicenter randomized controlled trial comparing the C-MAC D-Blade versus the GlideScope in a mixed provider and diverse patient population. Anesth Analg 2016; 122: 740-50.

140. Dhonneur G, Abdi W, Amathieu R, Ndoko S, Tual L. Optimising tracheal intubation success rate using the Airtraq laryngoscope. Anaesthesia 2009; 64: 315-9.

141. Downey A, Duggan LV, Law JA. A systematic review of metaanalyses comparing direct laryngoscopy with videolaryngscopy. Can J Anesth 2021; DOI: https://doi.org/10.1007/s12630-021-01921-7.

142. Kaji AH, Shover C, Lee J, et al. Video versus direct and augmented direct laryngoscopy in pediatric tracheal intubations. Acad Emerg Med 2020; 27: 394-402.

143. Hoshijima H, Denawa $Y$, Tominaga A, Nakamura $C$, Shiga $T$, Nagasaka $H$. Videolaryngoscope versus Macintosh 
laryngoscope for tracheal intubation in adults with obesity: a systematic review and meta-analysis. J Clin Anesth 2018; 44: 69-75.

144. Hypes CD, Stolz U, Sakles JC, et al. Video laryngoscopy improves odds of first-attempt success at intubation in the intensive care unit. A propensity-matched analysis. Ann Am Thorac Soc 2016; 13: 382-90.

145. Silverberg MJ, Li N, Acquah SO, Kory PD. Comparison of video laryngoscopy versus direct laryngoscopy during urgent endotracheal intubation: a randomized controlled trial. Crit Care Med 2015; 43: 636-41.

146. De Jong A, Molinari N, Conseil M, et al. Video laryngoscopy versus direct laryngoscopy for orotracheal intubation in the intensive care unit: a systematic review and meta-analysis. Intensive Care Med 2014; 40: 629-39.

147. Mosier JM, Whitmore SP, Bloom JW, et al. Video laryngoscopy improves intubation success and reduces esophageal intubations compared to direct laryngoscopy in the medical intensive care unit. Crit Care 2013; DOI: https://doi.org/10.1186/cc13061.

148. Lingappan $K$, Arnold JL, Fernandes CJ, Pammi $M$. Videolaryngoscopy versus direct laryngoscopy for tracheal intubation in neonates. Cochrane Database Syst Rev 2018; DOI: https://doi.org/10.1002/14651858.CD009975.pub3.

149. Kleine-Brueggeney $M$, Buttenberg $M$, Greif $R$, Nabecker $S$, Theiler $L$. Evaluation of three unchannelled videolaryngoscopes and the Macintosh laryngoscope in patients with a simulated difficult airway: a randomised, controlled trial. Anaesthesia 2017; 72: 370-8.

150. Pieters BM, Maas EH, Knape JT, van Zundert AA. Videolaryngoscopy vs. direct laryngoscopy use by experienced anaesthetists in patients with known difficult airways: a systematic review and meta-analysis. Anaesthesia 2017; 72: 1532-41.

151. Lewis SR, Butler AR, Parker J, Cook TM, Smith AF. Videolaryngoscopy versus direct laryngoscopy for adult patients requiring tracheal intubation. Cochrane Database Syst Rev 2016; DOI: https://doi.org/10.1002/14651858.CD011136. pub2.

152. Sakles JC, Patanwala AE, Mosier JM, Dicken JM. Comparison of video laryngoscopy to direct laryngoscopy for intubation of patients with difficult airway characteristics in the emergency department. Intern Emerg Med 2014; 9: 93-8.

153. Mosier JM, Stolz U, Chiu S, Sakles JC. Difficult airway management in the emergency department: GlideScope videolaryngoscopy compared to direct laryngoscopy. J Emerg Med 2012; 42: 629-34.

154. Sakles JC, Mosier JM, Patanwala AE, Dicken JM, Kalin L, Javedani $P P$. The $\mathrm{C}-\mathrm{MAC}(\mathrm{R})$ video laryngoscope is superior to the direct laryngoscope for the rescue of failed first-attempt intubations in the emergency department. J Emerg Med 2015; 48: $280-6$

155. Park R, Peyton JM, Fiadjoe JE, et al. The efficacy of GlideScope(R) videolaryngoscopy compared with direct laryngoscopy in children who are difficult to intubate: an analysis from the paediatric difficult intubation registry. $\mathrm{Br} \mathrm{J}$ Anaesth 2017; 119: 984-92.

156. Jiang $J, M a D$, Li B, Yue Y, Хue F. Video laryngoscopy does not improve the intubation outcomes in emergency and critical patients - a systematic review and meta-analysis of randomized controlled trials. Crit Care 2017; DOI: https://doi.org/10.1186/ s13054-017-1885-9.

157. Arulkumaran $N$, Lowe J, Ions $R$, Mendoza M, Bennett $V$, Dunser $M W$. Videolaryngoscopy versus direct laryngoscopy for emergency orotracheal intubation outside the operating room: a systematic review and meta-analysis. Br J Anaesth 2018; 120: $712-24$.
158. Lakticova V, Koenig SJ, Narasimhan M, Mayo PH. Video laryngoscopy is associated with increased first pass success and decreased rate of esophageal intubations during urgent endotracheal intubation in a medical intensive care unit when compared to direct laryngoscopy. J Intensive Care Med 2015; 30: 44-8.

159. Eisenberg MA, Green-Hopkins I, Werner H, Nagler J. Comparison between direct and video-assisted laryngoscopy for intubations in a pediatric emergency department. Acad Emerg Med 2016; 23: 870-7.

160. Saposnik G, Redelmeier D, Ruff CC, Tobler PN. Cognitive biases associated with medical decisions: a systematic review. BMC Med Inform Decis Mak 2016; DOI: https://doi.org/10. 1186/s12911-016-0377-1.

161. Carayon P, Wood KE. Patient safety - the role of human factors and systems engineering. Stud Health Technol Inform 2010; 153: 23-46.

162. Rognas L, Hansen TM, Kirkegaard H, Tonnesen E. Pre-hospital advanced airway management by experienced anaesthesiologists: a prospective descriptive study. Scand J Trauma Resusc Emerg Med 2013; DOI: https://doi.org/10.1186/ 1757-7241-21-58.

163. $\operatorname{Kim} J$, $\operatorname{Kim} K, \operatorname{Kim} T$, et al. The clinical significance of a failed initial intubation attempt during emergency department resuscitation of out-of-hospital cardiac arrest patients. Resuscitation 2014; 85: 623-7.

164. Sauer CW, Kong JY, Vaucher YE, et al. Intubation attempts increase the risk for severe intraventricular hemorrhage in preterm infants-a retrospective cohort study. J Pediatr 2016; 177: 108-13.

165. Lee JH, Turner DA, Kamat $P$, et al. The number of tracheal intubation attempts matters! A prospective multi-institutional pediatric observational study. BMC Pediatr 2016; DOI: https:// doi.org/10.1186/s12887-016-0593-y.

166. Stinson HR, Srinivasan V, Topjian AA, et al. Failure of invasive airway placement on the first attempt is associated with progression to cardiac arrest in pediatric acute respiratory compromise. Pediatr Crit Care Med 2018; 19: 9-16.

167. Mort TC. Emergency tracheal intubation: complications associated with repeated laryngoscopic attempts. Anesth Analg 2004; 99: 607-13.

168. Griesdale DE, Bosma TL, Kurth T, Isac G, Chittock DR. Complications of endotracheal intubation in the critically ill. Intensive Care Med 2008; 34: 1835-42.

169. Martin LD, Mhyre JM, Shanks AM, Tremper KK, Kheterpal S. 3,423 emergency tracheal intubations at a university hospital: airway outcomes and complications. Anesthesiology 2011; 114: 42-8.

170. Sakles JC, Chiu S, Mosier J, Walker C, Stolz U. The importance of first pass success when performing orotracheal intubation in the emergency department. Acad Emerg Med 2013; 20: 71-8.

171. Goto T, Watase H, Morita H, et al. Repeated attempts at tracheal intubation by a single intubator associated with decreased success rates in emergency departments: an analysis of a multicentre prospective observational study. Emerg Med J 2015; 32: 781-6.

172. Bodily JB, Webb HR, Weiss SJ, Braude DA. Incidence and duration of continuously measured oxygen desaturation during emergency department intubation. Ann Emerg Med 2016; 67: 389-95.

173. Apfelbaum JL, Hagberg CA, Caplan RA, et al. Practice guidelines for management of the difficult airway: an updated report by the American Society of Anesthesiologists Task Force on Management of the Difficult Airway. Anesthesiology 2013; 118: 251-70. 
174. Petrini F, Accorsi A, Adrario E, et al. Recommendations for airway control and difficult airway management. Minerva Anestesiol 2005; 71: 617-57.

175. Petrini F, Di Giacinto I, Cataldo R, et al. Perioperative and periprocedural airway management and respiratory safety for the obese patient: 2016 SIAARTI Consensus. Minerva Anestesiol 2016; 82: 1314-35.

176. Rehn M, Hyldmo PK, Magnusson V, et al. Scandinavian SSAI clinical practice guideline on pre-hospital airway management. Acta Anaesthesiol Scand 2016; 60: 852-64.

177. Myatra SN, Ahmed SM, Kundra P, et al. The All India Difficult Airway Association 2016 guidelines for tracheal intubation in the Intensive Care Unit. Indian J Anaesth 2016; 60: 922-30.

178. Sun F, Wang $Y$, Ma S, et al. Clinical consensus of emergency airway management. J Thorac Dis 2017; 9: 4599-606.

179. Australian and New Zealand College of Anaesthetists; Faculty of Pain Medicine. PS61 BP Guidelines for the Management of Evolving Airway Obstruction: Transition to the Can't Intubate Can't Oxygenate Airway Emergency. Available from URL: https://www.anzca.edu.au/getattachment/75c8066d-1f21-47d48102-8c3d81fb7ad2/PS61BP-Guideline-for-management-ofevolving-airway-obstruction-transition-to-CICO-BP (accessed March 2021).

180. Quintard H, l'Her E, Pottecher J, et al. Intubation and extubation of the ICU patient. Anaesth Crit Care Pain Med 2017; 36: 327-41.

181. Mushambi MC, Kinsella SM, Popat M, et al. Obstetric Anaesthetists' Association and Difficult Airway Society guidelines for the management of difficult and failed tracheal intubation in obstetrics. Anaesthesia 2015; 70: 1286-306.

182. Ramkumar $V$, Dinesh $E$, Shetty $S R$, et al. All India Difficult Airway Association 2016 guidelines for the management of unanticipated difficult tracheal intubation in obstetrics. Indian $\mathbf{J}$ Anaesth 2016; 60: 899-905.

183. Gruppo di Studio SIAARTI "Vie Aeree Difficili"; Frova G, Guarino A, Petrini $F$, et al. Recommendations for airway control and difficult airway management in paediatric patients. Minerva Anestesiol 2006; 72: 723-48.

184. Black AE, Flynn PE, Smith HL, Thomas ML, Wilkinson KA; Association of Pediatric Anaesthetists of Great Britain and Ireland. Development of a guideline for the management of the unanticipated difficult airway in pediatric practice. Paediatr Anaesth 2015; 25: 346-62.

185. Pawar DK, Doctor JR, Raveendra US, et al. All India Difficult Airway Association 2016 guidelines for the management of unanticipated difficult tracheal intubation in paediatrics. Indian J Anaesth 2016; 60: 906-14.

186. Galvez JA, Acquah S, Ahumada L, et al. Hypoxemia, bradycardia, and multiple laryngoscopy attempts during anesthetic induction in infants: a single-center, retrospective study. Anesthesiology 2019; 131: 830-9.

187. Amalric $M$, Larcher $R$, Brunot $V$, et al. Impact of videolaryngoscopy expertise on first-attempt intubation success in critically ill patients. Crit Care Med 2020; 48: e889-96.

188. Humphreys S, von Ungern-Sternberg BS, Skowno J, et al. Highflow oxygen for children's airway surgery: randomised controlled trial protocol (HAMSTER). BMJ Open 2019; DOI: https://doi.org/10.1136/bmjopen-2019-031873.

189. Norris A, Heidegger T. Limitations of videolaryngoscopy. Br J Anaesth 2016; 117: 148-50.

190. Paton L, Gupta S, Blacoe D. Successful use of sugammadex in a 'can't ventilate' scenario. Anaesthesia 2013; 68: 861-4.

191. Kleine-Brueggeney M, Theiler L, Urwyler N, Vogt A, Greif R. Randomized trial comparing the i-gel ${ }^{\mathrm{TM}}$ and Magill tracheal tube with the single-use ILMA ${ }^{\mathrm{TM}}$ and ILMA ${ }^{\mathrm{TM}}$ tracheal tube for fibreoptic-guided intubation in anaesthetized patients with a predicted difficult airway. Br J Anaesth 2011; 107: 251-7.

192. van Zundert TC, Wong DT, van Zundert AA. The LMASupreme $^{\mathrm{TM}}$ as an intubation conduit in patients with known difficult airways: a prospective evaluation study. Acta Anaesthesiol Scand 2013; 57: 77-81.

193. Lenhardt $R$, Burkhart MT, Brock GN, Kanchi-Kandadai S, Sharma R, Akca O. Is video laryngoscope-assisted flexible tracheoscope intubation feasible for patients with predicted difficult airway? A prospective, randomized clinical trial. Anesth Analg 2014; 118: 1259-65.

194. Pieters BM, Theunissen M, van Zundert AA. Macintosh blade videolaryngoscopy combined with rigid Bonfils intubation endoscope offers a suitable alternative for patients with difficult airways. Anesth Analg 2018; 126: 988-94.

195. Sowers $N$, Kovacs $G$. Use of a flexible intubating scope in combination with a channeled video laryngoscope for managing a difficult airway in the emergency department. J Emerg Med 2016; 50: 315-9.

196. Soltesz S, Alm P, Mathes A, Hellmich M, Hinkelbein J. The effect of neuromuscular blockade on the efficiency of facemask ventilation in patients difficult to facemask ventilate: a prospective trial. Anaesthesia 2017; 72: 1484-90.

197. Joffe AM, Ramaiah $R$, Donahue E, et al. Ventilation by mask before and after the administration of neuromuscular blockade: a pragmatic non-inferiority trial. BMC Anesthesiol 2015; DOI: https://doi.org/10.1186/s12871-015-0111-z.

198. Sachdeva R, Kannan TR, Mendonca C, Patteril M. Evaluation of changes in tidal volume during mask ventilation following administration of neuromuscular blocking drugs. Anaesthesia 2014; 69: 826-31.

199. Ikeda A, Isono $S$, Sato $Y$, et al. Effects of muscle relaxants on mask ventilation in anesthetized persons with normal upper airway anatomy. Anesthesiology 2012; 117: 487-93.

200. Simons DJ, Rensink RA. Change blindness: past, present, and future. Trends Cogn Sci 2005; 9: 16-20.

201. Jensen MS, Yao R, Street WN, Simons DJ. Change blindness and inattentional blindness. Wiley Interdiscip Rev Cogn Sci 2011; 2: 529-46.

202. Pattni N, Arzola C, Malavade A, Varmani S, Krimus L, Friedman Z. Challenging authority and speaking up in the operating room environment: a narrative synthesis. Br J Anaesth 2019; 122: 233-44.

203. Nielsen RP, Nikolajsen L, Paltved C, Aagaard R. Effect of simulation-based team training in airway management: a systematic review. Anaesthesia 2021; DOI: https://doi.org/10. 1111/anae. 15375.

204. Dillon JK, Christensen B, Fairbanks T, Jurkovich G, Moe KS. The emergent surgical airway: cricothyrotomy vs. tracheotomy. Int J Oral Maxillofac Surg 2013; 42: 204-8.

205. Duggan LV, Lockhart SL, Cook TM, O'Sullivan EP, Dare T, Baker PA. The Airway App: exploring the role of smartphone technology to capture emergency front-of-neck airway experiences internationally. Anaesthesia 2018; 73: 703-10.

206. Aziz S, Foster E, Lockey DJ, Christian MD. Emergency scalpel cricothyroidotomy use in a prehospital trauma service: a 20-year review. Emerg Med J 2021; DOI: https://doi.org/10.1136/ emermed-2020-210305.

207. Law JA. Deficiencies in locating the cricothyroid membrane by palpation: we can't and the surgeons can't, so what now for the emergency surgical airway? Can J Anesth 2016; 63: 791-6.

208. Drew T, McCaul CL. Laryngeal handshake technique in locating the cricothyroid membrane: a non-randomised comparative study. Br J Anaesth 2018; 121: 1173-8. 
209. Cook TM, Harrop-Griffiths AW, Whitaker DK, McNarry AF, Patel A, McGuire B. The 'No Trace=Wrong Place' campaign. Br J Anaesth 2019; 122: e68-9.

210. Kim MS, Park JH, Lee KY, et al. Influence of head and neck position on the performance of supraglottic airway devices: a systematic review and meta-analysis. PLoS One 2019; DOI: https://doi.org/10.1371/journal.pone.0216673.

211. Cook TM, Kelly FE, Goswami A. 'Hats and caps' capnography training on intensive care. Anaesthesia 2013; DOI: https://doi. org/10.1111/anae.12173.

212. Linko K, Paloheimo M, Tammisto T. Capnography for detection of accidental oesophageal intubation. Acta Anaesthesiol Scand 1983; 27: 199-202.

213. Vithalani VD, Vlk $S$, Davis $S Q$, Richmond NJ. Unrecognized failed airway management using a supraglottic airway device. Resuscitation 2017; 119: 1-4.

214. Link MS, Berkow LC, Kudenchuk PJ, et al. Part 7: Adult Advanced Cardiovascular Life Support: 2015 American Heart Association guidelines update for cardiopulmonary resuscitation and emergency cardiovascular care. Circulation 2015; 132(18 Suppl 2): S444-64.

215. Cook TM, Nolan JP. Use of capnography to confirm correct tracheal intubation during cardiac arrest. Anaesthesia 2011; 66: 1183-4.

216. Jafferji D, Morris R, Levy N. Reducing the risk of confirmation bias in unrecognised oesophageal intubation. Br J Anaesth 2019; 122: e66-8.

217. Takeda T, Tanigawa K, Tanaka H, Hayashi Y, Goto E, Tanaka $K$. The assessment of three methods to verify tracheal tube placement in the emergency setting. Resuscitation 2003; 56: 153-7.

218. Grmec S. Comparison of three different methods to confirm tracheal tube placement in emergency intubation. Intensive Care Med 2002; 28: 701-4.

219. Grmec S, Mally S. Prehospital determination of tracheal tube placement in severe head injury. Emerg Med J 2004; 21: 518-20.

220. Goldberg JS, Rawle PR, Zehnder JL, Sladen RN. Colorimetric end-tidal carbon dioxide monitoring for tracheal intubation. Anesth Analg 1990; 70: 191-4.

221. Knapp S, Kofler J, Stoiser B, et al. The assessment of four different methods to verify tracheal tube placement in the critical care setting. Anesth Analg 1999; 88: 766-70.

222. Gomes SB, Mychaskiw G 2nd. Failure of the Easy Cap II CO2 detector to indicate esophageal intubation. J Clin Anesth 2012; 24: 352-3.

223. Ornato JP, Shipley JB, Racht EM, et al. Multicenter study of a portable, hand-size, colorimetric end-tidal carbon dioxide detection device. Ann Emerg Med 1992; 21: 518-23.

224. Anton WR, Gordon RW, Jordan TM, Posner KL, Cheney FW. A disposable end-tidal $\mathrm{CO} 2$ detector to verify endotracheal intubation. Ann Emerg Med 1991; 20: 271-5.

225. MacLeod BA, Heller MB, Gerard J, Yealy DM, Menegazzi JJ. Verification of endotracheal tube placement with colorimetric end-tidal CO2 detection. Ann Emerg Med 1991; 20: 267-70.

226. Bhende MS, Thompson AE. Evaluation of an end-tidal $\mathrm{CO} 2$ detector during pediatric cardiopulmonary resuscitation. Pediatrics 1995; 95: 395-9.

227. Schmolzer GM, Poulton DA, Dawson JA, Kamlin CO, Morley $C J$, Davis $P G$. Assessment of flow waves and colorimetric $\mathrm{CO} 2$ detector for endotracheal tube placement during neonatal resuscitation. Resuscitation 2011; 82: 307-12.

228. Srinivasa $V$, Kodali BS. Caution when using colorimetry to confirm endotracheal intubation. Anesth Analg 2007; DOI: https://doi.org/10.1213/01.ane.0000253918.18547.13.

229. Hughes SM, Blake BL, Woods SL, Lehmann CU. False-positive results on colorimetric carbon dioxide analysis in neonatal resuscitation: potential for serious patient harm. J Perinatol 2007; 27: 800-1.

230. Kovacs $G$, Duggan $L V$, Brindley $P G$. Glottic impersonation. Can J Anesth 2017; DOI: https://doi.org/10.1007/s12630-016-0804$\mathrm{x}$.

231. Alabbad SI, Shaw K, Puligandla PS, Carranza R, Bernard C, Laberge JM. The pitfalls of endotracheal intubation beyond the fistula in babies with type $\mathrm{C}$ esophageal atresia. Semin Pediatr Surg 2009; 18: 116-8.

232. Taneja B, Saxena $K N$. Endotracheal intubation in a neonate with esophageal atresia and trachea-esophageal fistula: pitfalls and techniques. J Neonatal Surg 2014; DOI: https://doi.org/10. 47338/jns.v3.82.

233. Lin MJ, Gurley K, Hoffmann B. Bedside ultrasound for tracheal tube verification in pediatric emergency department and ICU patients: a systematic review. Pediatr Crit Care Med 2016; 17 : e469-76.

234. Gottlieb M, Holladay D, Peksa GD. Ultrasonography for the confirmation of endotracheal tube intubation: a systematic review and meta-analysis. Ann Emerg Med 2018; 72: 627-36.

235. Das SK, Choupoo NS, Haldar R, Lahkar A. Transtracheal ultrasound for verification of endotracheal tube placement: a systematic review and meta-analysis. Can J Anesth 2015; 62: 413-23.

236. Chou EH, Dickman E, Tsou PY, et al. Ultrasonography for confirmation of endotracheal tube placement: a systematic review and meta-analysis. Resuscitation 2015; 90: 97-103.

237. Andersen $K H$, Hald A. Assessing the position of the tracheal tube. The reliability of different methods. Anaesthesia 1989; 44: 984-5.

238. Qi L, Liu R, Tang E, et al. A comparison of degree of precision of auscultation, partial pressure of carbon dioxide in endexpiration, and transillumination technique in verifying accurate position of endotracheal tube (Chinese). Zhonghua Wei Zhong Bing Ji Jiu Yi Xue 2015; 27: 826-30.

239. Sharieff $G Q$, Rodarte A, Wilton $N$, Bleyle D. The self-inflating bulb as an airway adjunct: is it reliable in children weighing less than 20 kilograms? Acad Emerg Med 2003; 10: 303-8.

240. Sharieff $G Q$, Rodarte A, Wilton N, Silva PD, Bleyle D. The selfinflating bulb as an esophageal detector device in children weighing more than twenty kilograms: a comparison of two techniques. Ann Emerg Med 2003; 41: 623-9.

241. Heidegger T, Heim C. Esophageal detector device: not always reliable. Ann Emerg Med 1996; DOI: https://doi.org/10.1016/ s0196-0644(96)70125-7.

242. Marley CD Jr, Eitel DR, Anderson TE, Murn AJ, Patterson GA. Evaluation of a prototype esophageal detection device. Acad Emerg Med 1995; 2: 503-7.

243. Kasper $C L$, Deem $S$. The self-inflating bulb to detect esophageal intubation during emergency airway management. Anesthesiology 1998; 88: 898-902.

244. Wafai Y, Salem MR, Joseph NJ, Baraka A. The self-inflating bulb for confirmation of tracheal intubation: incidence and demography of false negatives. Anesthesiology 1994; 81(3A): A1303.

245. Wee MY, Walker AK. The oesophageal detector device. An assessment with uncuffed tubes in children. Anaesthesia 1991; 46: 869-71.

246. Salem MR, Wafai Y, Baraka A, Taimorrazy B, Joseph NJ, Nimmagadda $U$. Use of the self-inflating bulb for detecting esophageal intubation after "esophageal ventilation". Anesth Analg 1993; 77: 1227-31.

247. Haridas RP. Condensation on tracheal tubes is commonly seen with oesophageal intubation. Br J Anaesth 1995; 75: 115-6.

248. Gillespie JH, Knight RG, Middauch RE, Menk EJ, Baysinger $C L$. Efficacy of endotracheal tube cuff palpation and humidity in 
distinguishing endotracheal from esophageal intubation. Anesthesiology 1988; 69(Suppl. 3A): A265.

249. Pollard $R$, Wagner $M$, Grichnik $K$, Clyne BC, Habib AS. Prevalence of difficult intubation and failed intubation in a diverse obstetric community-based population. Curr Med Res Opin 2017; 33: 2167-71.

250. Quinn AC, Milne D, Columb M, Gorton H, Knight M. Failed tracheal intubation in obstetric anaesthesia: $2 \mathrm{yr}$ national casecontrol study in the UK. Br J Anaesth 2013; 110: 74-80.

251. Djabatey EA, Barclay PM. Difficult and failed intubation in 3430 obstetric general anaesthetics. Anaesthesia 2009; 64: 1168-71.

252. Palanisamy A, Mitani AA, Tsen LC. General anesthesia for cesarean delivery at a tertiary care hospital from 2000 to 2005: a retrospective analysis and 10-year update. Int J Obstet Anesth 2011; 20: 10-6.

253. Boutonnet M, Faitot V, Katz A, Salomon L, Keita H. Mallampati class changes during pregnancy, labour, and after delivery: can these be predicted? Br J Anaesth 2010; 104: 67-70.

254. Mushambi MC, Athanassoglou V, Kinsella SM. Anticipated difficult airway during obstetric general anaesthesia: narrative literature review and management recommendations. Anaesthesia 2020; 75: 945-61.

255. Kodali BS, Chandrasekhar S, Bulich LN, Topulos GP, Datta S. Airway changes during labor and delivery. Anesthesiology 2008; 108: 357-62.

256. You-Ten KE, Desai D, Postonogova T, Siddiqui N. Accuracy of conventional digital palpation and ultrasound of the cricothyroid membrane in obese women in labour. Anaesthesia 2015; 70: $1230-4$.

257. Teoh WH, Kristensen MS. Ultrasonographic identification of the cricothyroid membrane. Anaesthesia 2014; 69: 649-50.

258. Au K, Shippam W, Taylor J, Albert A, Chau A. Determining the effective pre-oxygenation interval in obstetric patients using high-flow nasal oxygen and standard flow rate facemask: a biased-coin up-down sequential allocation trial. Anaesthesia 2020; 75: 609-16.

259. Shippam W, Preston R, Douglas J, Taylor J, Albert A, Chau A. High-flow nasal oxygen vs. standard flow-rate facemask preoxygenation in pregnant patients: a randomised physiological study. Anaesthesia 2019; 74: 450-6.

260. Tan PC, Millay OJ, Leeton L, Dennis AT. High-flow humidified nasal preoxygenation in pregnant women: a prospective observational study. Br J Anaesth 2019; 122: 86-91.

261. Phillips S, Subair S, Husain T, Sultan P. Apnoeic oxygenation during maternal cardiac arrest in a parturient with extreme obesity. Int J Obstet Anesth 2017; 29: 88-90.

262. Howle R, Onwochei D, Harrison SL, Desai N. Comparison of videolaryngoscopy and direct laryngoscopy for tracheal intubation in obstetrics: a mixed-methods systematic review and meta-analysis. Can J Anesth 2021; 68: 546-65.

263. Habib AS. Is it time to revisit tracheal intubation for cesarean delivery? Can J Anesth 2012; 59: 642-7.

264. Fang X, Xiao $Q$, Xie $Q$, et al. General anesthesia with the use of SUPREME laryngeal mask airway for emergency cesarean delivery: a retrospective analysis of 1039 parturients. Sci Rep 2018; DOI: https://doi.org/10.1038/s41598-018-31581-5.

265. Metodiev Y, Mushambi M. Supraglottic airway devices for caesarean delivery under general anaesthesia: for all, for none, or for some? Br J Anaesth 2020; 125: e7-11.

266. Bamber J, Lucas N; MBRRACE-UK Indirect Chapter-Writing Group. Improving anaesthetic care. In: Knight M, Bunch K, Tuffnell D, Shakespeare J, Kotnis R, Kenyon S, Kurinczuk JJ (Eds) on behalf of MBRRACE-UK. Saving Lives, Improving Mothers' Care - Lessons learned to inform maternity care from the UK and Ireland Confidential Enquiries into Maternal Deaths and Morbidity 2016-18. Oxford: National Perinatal Epidemiology Unit, University of Oxford; 2020: 43-7.

267. Hawkins JL, Chang J, Palmer SK, Gibbs CP, Callaghan WM. Anesthesia-related maternal mortality in the United States: 1979-2002. Obstet Gynecol 2011; 117: 69-74.

268. Bunchungmongkol N, Somboonviboon W, Suraseranivongse S, Vasinanukorn M, Chau-in W, Hintong T. Pediatric anesthesia adverse events: the Thai Anesthesia Incidents Study (THAI Study) database of 25,098 cases. J Med Assoc Thai 2007; 90: 2072-9.

269. Engelhardt T, Fiadjoe JE, Weiss $M$, et al. A framework for the management of the pediatric airway. Paediatr Anaesth 2019; 29: 985-92.

270. Weingart SD, Levitan RM. Preoxygenation and prevention of desaturation during emergency airway management. Ann Emerg Med 2012; 59: 165-75.e1.

271. Huang AS, Sarver A, Widing A, Hajduk J, Jagannathan N. The design of the perfect pediatric supraglottic airway device. Paediatr Anaesth 2020; 30: 280-7.

272. Burjek NE, Nishisaki A, Fiadjoe JE, et al. Videolaryngoscopy versus fiber-optic intubation through a supraglottic airway in children with a difficult airway: an analysis from the multicenter pediatric difficult intubation registry. Anesthesiology 2017; 127: 432-40.

273. Jagannathan N, Sohn LE, Mankoo R, Langen KE, Mandler T. A randomized crossover comparison between the Laryngeal Mask Airway-Unique ${ }^{\mathrm{TM}}$ and the air-Q intubating laryngeal airway in children. Paediatr Anaesth 2012; 22: 161-7.

274. Weiss M, Engelhardt T. Using cuffed tracheal tubes below recommended body weight: compromising safety or exploring limits safely? Paediatr Anaesth 2018; 28: 193-4.

275. Johansen K, Holm-Knudsen RJ, Charabi B, Kristensen MS, Rasmussen LS. Cannot ventilate-cannot intubate an infant: surgical tracheotomy or transtracheal cannula? Paediatr Anaesth 2010; 20: 987-93.

276. Morrison S, Aerts S, Saldien V. The Ventrain device: a future role in difficult airway algorithms? A A Pract 2019; 13: 362-5.

277. Mann CM, Baker PA, Sainsbury DM, Taylor R. A comparison of cannula insufflation device performance for emergency front of neck airway. Paediatr Anaesth 2021; DOI: https://doi.org/10. 1111/pan.14128.

278. Flin R, Fioratou E, Frerk C, Trotter C, Cook TM. Human factors in the development of complications of airway management: preliminary evaluation of an interview tool. Anaesthesia 2013; 68: $817-25$.

279. Rozenfeld RA, Nannicelli AP, Brown AR, et al. Verbal communication during airway management and emergent endotracheal intubation: observations of team behavior among multi-institutional pediatric intensive care unit in situ simulations. J Patient Saf 2016; DOI: https://doi.org/10.1097/ PTS.0000000000000272.

280. Petrosoniak A, Hicks CM. Beyond crisis resource management: new frontiers in human factors training for acute care medicine. Curr Opin Anaesthesiol 2013; 26: 699-706.

281. Janz DR, Semler MW, Joffe AM, et al. A multicenter randomized trial of a checklist for endotracheal intubation of critically ill adults. Chest 2018; 153: 816-24.

282. Burgess MR, Crewdson K, Lockey DJ, Perkins ZB. Prehospital emergency anaesthesia: an updated survey of UK practice with emphasis on the role of standardisation and checklists. Emerg Med J 2018; 35: 532-7.

283. Hardy G, Horner D. BET 2: should real resuscitationists use airway checklists? Emerg Med J 2016; 33: 439-41.

284. Turner JS, Bucca AW, Propst SL, et al. Association of checklist use in endotracheal intubation with clinically important outcomes: a systematic review and meta-analysis. JAMA 
Netw Open 2020; DOI: https://doi.org/10.1001/ jamanetworkopen.2020.9278.

285. Schulz CM, Burden A, Posner KL, et al. Frequency and type of situational awareness errors contributing to death and brain damage: a closed claims analysis. Anesthesiology 2017; 127: 326-37.

286. LeBlanc VR. The effects of acute stress on performance: implications for health professions education. Acad Med 2009; 84(10 Suppl): S25-33.

287. Salik I, Ashurst JV. Closed Loop Communication Training in Medical Simulation. Treasure Island, FL: StatPearls; 2020 .

288. McNarry AF, Cook TM, Baker PA, O'Sullivan EP. The airway lead: opportunities to improve institutional and personal preparedness for airway management. Br J Anaesth 2020; 125: e22-4.

289. Lundstrom LH, Moller AM, Rosenstock C, et al. A documented previous difficult tracheal intubation as a prognostic test for a subsequent difficult tracheal intubation in adults. Anaesthesia 2009; 64: 1081-8.

290. Scott Beattie W, Culwick MD, Grocott HP. Canadian Anesthesia Incident Reporting System (CAIRS): the Canadian Anesthesiologists' Society's National Patient Safety Initiative. Can J Anesth 2018; 65: 749-56.

291. Shanahan E, Huang JH, Chen A, Narsimhan A, Tang $R$. Difficultintubationapp.com - a difficult airway electronic record. Can J Anesth 2016; 63: 1299-300.

292. Ericsson $K A$. Acquisition and maintenance of medical expertise: a perspective from the expert-performance approach with deliberate practice. Acad Med 2015; 90: 1471-86.

293. Pusic MV, Kessler D, Szyld D, Kalet A, Pecaric M, Boutis K. Experience curves as an organizing framework for deliberate practice in emergency medicine learning. Acad Emerg Med 2012; 19: 1476-80.

294. Ericsson KA. Deliberate practice and acquisition of expert performance: a general overview. Acad Emerg Med 2008; 15: 988-94.

295. Issenberg SB, McGaghie WC, Petrusa ER, Lee Gordon D, Scalese RJ. Features and uses of high-fidelity medical simulations that lead to effective learning: a BEME systematic review. Med Teach 2005; 27: 10-28.

296. Bould MD, Crabtree NA, Naik VN. Assessment of procedural skills in anaesthesia. Br J Anaesth 2009; 103: 472-83.

297. Baker PA, Greif RT. Airway management education. In: Hagberg CA, Artime C, Aziz MF, editors. Hagberg and Benumof's Airway Management. 4th ed. Philadelphia: Elsevier; 2018. p. 891-910.

298. Alfery DD, Ezri T, Ghelber $O$, Szmuk $P$. Teaching airway management is dependent on the knowledge of the teachers. Acta Anaesthesiol Scand 2006; 50: 895-6; author reply 896-7.

299. Crosby ET. An evidence-based approach to airway management: is there a role for clinical practice guidelines? Anaesthesia 2011; 66(Suppl 2): 112-8.

300. Chrimes N, Cook TM. Critical airways, critical language. Br J Anaesth 2017; 118: 649-54.

301. Chrimes N, Higgs A, Sakles JC. Welcome to the era of universal airway management. Anaesthesia 2020; 75: 711-5.

Publisher's Note Springer Nature remains neutral with regard to jurisdictional claims in published maps and institutional affiliations. 